\title{
Desigualdade de acesso a serviços de saneamento ambiental nos municípios brasileiros: \\ Evidências de uma Curva de Kuznets e de uma \\ Seletividade Hierárquica das Políticas?
}

Carlos César Santejo Saiani
IE-UFU
Rudinei Toneto Júnior
FEARP-USP
Juscelino Dourado
ESALQ-USP

\section{Palavras-chave}

Saneamento ambiental,

Curva de Kuznets,

Seletividade Hierárquica.

Classificação JEL H42, L95, Q56.

\section{Key words}

environmental sanitation, Kuznets curve, hierarchical selection

JEL Classification H42, L95, Q56

\section{Resumo}

O principal objetivo do artigo foi verificar a relação entre a desigualdade de acesso aos serviços de saneamento ambiental e a renda dos domicílios. Além disso, foi analisado se a desigualdade de acesso é influenciada por outras variáveis relacionadas à oferta dos serviços, em especial, pelos aspectos políticos. Três hipóteses foram testadas: (i) se existe relação positiva entre a desigualdade de acesso e a desigualdade de renda; (ii) se a relação entre a desigualdade de acesso aos serviços e à renda per capita é semelhante à Curva de Kuznets (CK); e (iii) se existe Seletividade Hierárquica das Políticas (SHP) nesses serviços. Os resultados obtidos para os municípios brasileiros nos anos 1991 e 2000 sinalizaram a existência de uma SHP nos três serviços considerados, mas a CK se verificou apenas no abastecimento de água.

\section{Abstract}

The main objective of this paper was to evaluate the relation between the inequality of access to environmental sanitation services and household income. In addition to that, it was analyzed whether the inequality of access is influenced by other variables related to supply of services, mainly the political aspects. Three hypotheses were verified: (i) if there is a positive relation between the inequality of access to sanitation services and inequality of income; (ii) if this relation between inequality of access to sanitation services and per capita income is similar to the Kuznets Curve (KC); and (iii) if there is a Hierarchical selection of Policies (HSP) in these services. The results for the Brazilian cities in the years 1991 and 2000 suggest the existence of hierarchical selection in the three services considered, and the Kuznets Curve only in the water supply service. 


\section{1_Introdução}

O saneamento ambiental, que abrange os serviços de abastecimento de água, de esgotamento sanitário (coleta e tratamento), de manejo de resíduos sólidos (lixo) urbanos (coleta e disposição) e de manejo de águas pluviais urbanas, é um importante instrumento de controle dos impactos da urbanização sobre o meio ambiente e de redução dos riscos naturais.

A ausência de condições adequadas no setor pode contribuir para a contaminação dos mananciais, cursos de água e solos, para o assoreamento dos rios, para as inundações e, consequentemente, para a formaçáo de ambientes propícios à proliferaçáo de agentes transmissores de doenças. Estas, ao debilitarem os trabalhadores e os afastarem do trabalho, reduzem a produtividade, a produção - que também é afetada pelos impactos sobre o meio ambiente - e, assim, geram perdas econômicas.

Trata-se, portanto, de serviços essenciais com externalidades sobre o meio ambiente, a saúde dos indivíduos e o desenvolvimento econômico. Por isso, merecem atenção especial da esfera pública. No Brasil, eles são ofertados, predominantemente, por prestadores públicos. Se estes estivessem preocupados apenas com os retornos sociais, deveria haver certa equidade na cobertura. Contudo, isso não se observa na prática, uma vez que o aces- so tende a se elevar à medida que a renda per capita dos indivíduos (domicílios) aumenta. Ou seja, existe desigualdade de acesso aos serviços em função da renda dos consumidores (Saiani, 2006).

Essa desigualdade de acesso pode ser uma decorrência direta da própria capacidade desigual dos domicílios de pagarem o custo de ligação e as tarifas mensais pela utilização dos serviços. Além disso, os consumidores optam pela adesão a esses se forem conscientes dos benefícios que podem ser gerados, o que depende de aspectos culturais e educacionais, correlacionados positivamente com a renda. Esses fatores explicariam a distribuição não uniforme da cobertura dos serviços pelo lado da demanda, de modo que deveria existir relação positiva entre a desigualdade de acesso e a desigualdade de renda. O presente estudo pretende testar essa hipótese, para o caso dos municípios brasileiros.

Um importante tema da literatura sobre distribuição de renda é a existência ou não da chamada Curva de Kuznets (CK). Trata-se da hipótese de que existiria uma relação no formato de um "U-invertido" entre a desigualdade de renda e o desenvolvimento econômico. Ou seja, a desigualdade aumentaria em estágios iniciais de desenvolvimento e passaria a diminuir a partir de certo estágio. Estudos mais recentes defendem que essa relação 
${ }^{1}$ Ver: Bagolin et al. (2004); Bêrni et al. (2004); Jacinto; Tejada (2004); Salvato et al. (2006); Barros; Gomes (2008); Figueiredo et al. (2011). não se sustentaria no longo prazo, de modo que a desigualdade voltaria a aumentar em níveis mais avançados de desenvolvimento. Assim, a CK teria, na verdade, o formato de um "N".

Algumas evidências ambíguas da existência dessa relação, nos dois formatos, já foram encontradas para o caso dos municípios brasileiros. ${ }^{1}$ Se a desigualdade de renda tiver como consequência a desigualdade de acesso aos serviços de saneamento ambiental, entáo esta também deveria apresentar relação, no mesmo formato, com o desenvolvimento econômico. Essa é a segunda hipótese que será testada no estudo.

Pode-se questionar ainda se a desigualdade de acesso aos serviços decorreria de questóes relacionadas à oferta, e não somente à demanda. Mais especificamente, por se tratar de um setor no qual a provisão pública é preponderante, se aspectos políticos influenciariam o problema. Uma hipótese da Sociologia é a de que poderia existir Seletividade Hierárquica das Politicas (SHP), no sentido de que algumas políticas seriam adotadas para beneficiar prioritariamente, e com melhor qualidade, os grupos sociais mais ricos e escolarizados; posteriormente, beneficiariam os demais cidadãos (Marques, 2000). No caso do saneamento ambiental, pode-se pensar que, se isso for válido, no início da consolidação do serviço, a desigualdade de acesso au- mentaria, mas, atingido certo grau de cobertura, ela passaria a diminuir. Essa é a terceira hipótese a ser testada.

Portanto, o presente estudo pretende avaliar a questão da desigualdade de acesso a serviços de saneamento ambiental em função da renda dos indivíduos (domicílios), apontando se esta é determinada apenas pela capacidade de pagamento desigual dos consumidores ou se aspectos relacionados à oferta, principalmente políticos, também devem ser considerados. Para atingir o objetivo proposto, são realizadas estimaçôes para um painel de municípios brasileiros com dados referentes aos anos $1991 \mathrm{e}$ 2000, coletados nos Censos Demográficos dos respectivos anos, realizados pelo IBGE.

Em razão da disponibilidade de informações, são considerados três serviços de saneamento ambiental:

(i) coleta de lixo;

(ii) coleta de esgoto; $\mathrm{e}$

(iii) abastecimento de água.

A análise dos três serviços possibilita a obtenção de evidências mais robustas. Para se testar a robustez dos resultados, também são realizadas estimaçóes retirando da amostra os municípios que, no período, concederam os serviços à iniciativa privada. Dessa forma, são desconsiderados potenciais efeitos da privatização sobre os resultados.

Trata-se de um estudo que se justifica por ajudar a preencher uma lacuna na 
literatura, dado que, apesar da importância do tema, não há muitos trabalhos que discutem o problema da desigualdade de acesso a serviços de saneamento ambiental. Além disso, não foi encontrado nenhum outro estudo que tenha testado se essa apresenta uma relação do tipo da CK com o desenvolvimento econômico. A hipótese da SHP, por sua vez, foi avaliada por Bichir (2009), que comparou as políticas voltadas para a área central e para a área periférica no município de São Paulo. Aqui, é proposta uma forma mais ampla para testar essa hipótese, considerando o diferencial de renda entre os domicílios e utilizando dados em painel.

$\mathrm{O}$ artigo divide-se em quatro seçôes, além desta introdução e das considerações finais. Na segunda seção, é realizada uma revisão da literatura sobre a $\mathrm{CK}$, na qual são apresentadas as possíveis justificativas para a existência de tal relação. $\mathrm{Na}$ terceira seção, os indicadores de desigualdade de acesso aos serviços de saneamento ambiental em função do perfil de renda dos domicílios, construídos neste estudo, são apresentados e, por meio desses, é realizada uma caracterização do problema. Além disso, são discutidos possíveis determinantes da desigualdade de acesso, destacando-se a possibilidade da existência de uma SHP. As estratégias de estimação utilizadas para o teste dessa hipótese, assim co- mo da hipótese da CK, são apresentadas na quarta seção. Finalmente, na quinta seção, os resultados são analisados.

\section{2_Curva de Kuznets: possíveis justificativas e formatos}

Ao analisar os casos da Inglaterra, da Alemanha e dos Estados Unidos, nos séculos XIX e XX, Kuznets (1955) observou que a desigualdade de renda aumentava em níveis menores de renda per capita e diminuía em níveis maiores. Existiria, assim, relaçáo no formato de um "U-invertido", não necessariamente simétrico, entre o desenvolvimento econômico e a desigualdade de renda. Essa relação ficou conhecida como Curva de Kuznets (CK).

Após essa constatação inicial, diversos estudos avaliaram a validade da CK. A hipótese foi testada por diferentes métodos, com várias medidas de desigualdade de renda e de desenvolvimento econômico e para amostras e períodos distintos, inclusive para o caso dos municípios brasileiros. ${ }^{2}$ Alguns trabalhos apresentaram a relação apenas como um fato estilizado, enquanto outros tentaram justificá-la. Deutsch e Silber (2000) dividem os estudos que apresentaram explicaçóes para CK em três grupos, de acordo com a abordagem utilizada:

(i) economia dual;
${ }^{2}$ Alguns resultados internacionais podem ser avaliados nos surveys realizados por Deutsch e Silber (2000) e Piketty (2006).

Para o caso dos municípios brasileiros, ver: Bagolin et al. (2004), Bêrni et al (2004), Jacinto e Tejada (2004), Salvato et al (2006), Barros e Gomes (2008) e Figueiredo et al (2011). 
${ }^{3}$ Ver Dahan e Tsiddon (1998)

e Aghion e Bolton (1992),

respectivamente. (ii) teorias de crescimento endógeno; e

(iii) teoria da escolha pública.

A abordagem da economia dual justifica a CK por meio da hipótese de que a migração da população entre setores da economia, do menos para o mais dinâmico - ou do tradicional para o moderno -, causaria aumento inicial da desigualdade de renda e posterior redução. O próprio Kuznets (1955) utilizou essa abordagem, fundamentando a explicação da relação no diferencial de rendimentos entre atividades agrícolas e atividades industriais. De acordo com o autor, à medida que a renda de uma economia cresce, a produtividade marginal do trabalho nas atividades urbanas (industriais) aumenta mais rapidamente do que nas atividades rurais (agrícolas), elevando a desigualdade de renda entre as áreas rural e urbana. Ao longo do tempo, a migração da população das atividades agrícolas para as atividades industriais, motivada pelo diferencial de rendimento, diminui a desigualdade de renda.

Para Glaeser (2005), o efeito da industrialização se refletiria ainda por meio das políticas redistributivas. Segundo o autor, o esforço público para gerar tais políticas aumenta à medida que a urbanização se eleva e que, em razão da maior proximidade, as pessoas conseguem se organizar e exercer maior pressão para o atendi- mento de suas demandas. Tal justificativa também está alinhada à teoria da escolha pública, comentada mais adiante.

O principal argumento defendido pelos estudos relacionados às teorias de crescimento endógeno é que, no início do desenvolvimento econômico, uma distribuição desigual do capital humano - e, consequentemente, da renda - seria condição necessária para que ocorressem investimentos nesse tipo de capital e para que a economia se desenvolvesse. Contudo, ao longo do tempo, sucederia um "transbordamento" (trickle-down) do conhecimento para os seguimentos mais pobres, reduzindo a desigualdade de renda (Galor; Tsiddon, 1996). Seguindo essa linha de raciocínio, transiçóes demográficas e imperfeiçóes dos mercados de capitais são argumentos utilizados para explicar a relação $\mathrm{CK}^{3}$

Os estudos relacionados à teoria da escolha pública, por sua vez, levam em conta a interação entre o mecanismo político e a estrutura econômica, sendo a participação política considerada como exógena em alguns, e endógenas, em outros. Entre os trabalhos que consideram a participação política como exógena, um dos argumentos utilizados para justificar a CK seria o efeito regressivo da tributação, que aumentaria a desigualdade nos estágios iniciais de desenvolvimento. À medida que 
a arrecadação fosse utilizada para investimentos em capital físico e em capital humano e para políticas redistributivas, a desigualdade tenderia a diminuir (Alesina; Rodrik, 1994).

Além disso, alguns estudos defendem a hipótese de que, quanto mais elevada for a desigualdade renda, maior seria a demanda por políticas redistributivas, o que poderia ocorrer mesmo se o eleitor mediano não pertencesse ao grupo com menor renda, caso esse fosse motivado por altruísmo ou, conforme aponta Varian (1980), se desejasse tais políticas como uma forma de seguro social, para impedir que sua renda diminua abaixo de um valor mínimo caso ocorra alguma eventualidade, como a perda do emprego. Assim, maior seria a probabilidade de sucesso eleitoral dos candidatos que propusessem e depois implantassem políticas redistributivas (Perotti, 1993; Glaeser, 2005).

Segundo Glaeser (2005), a heterogeneidade étnica é outro fator que influenciaria a adoção de políticas redistributivas, $\mathrm{o}$ que decorreria da hipótese de que as pessoas teriam menor preferência por políticas que beneficiassem indivíduos que não pertencessem a sua etnia. É importante ressaltar que maior fracionalização étnica também poderia impactar diretamente sobre a desigualdade de renda, em função de potenciais diferenças de habilidades dos indivíduos pertencentes a grupos étnicos distintos (Alesina; Glaeser, 2004).

Os trabalhos que consideram a participação política como endógena defendem que essa possui relação positiva com o nível de educação (ou de habilidades). Argumenta-se que, nos estágios iniciais de desenvolvimento, apenas um grupo restrito da população conseguiria investir em capital humano e, consequentemente, deteria o controle sobre o processo político, ocorrendo baixo esforço para a implantação de políticas redistributivas, o que aumentaria a desigualdade de renda. À medida que a economia se desenvolvesse, mais pessoas conseguiriam acumular capital humano e, assim, passariam a ter participação política, o que poderia aumentar a adoção de políticas redistributivas (Gradstein; Justman, 1999).

Um importante estudo que chegou a resultados que apontaram uma nova direção para o debate sobre a relação de longo prazo entre desigualdade de renda e desenvolvimento econômico foi o de List e Gallet (1999). Motivados por alguns trabalhos que mostraram evidências de aumento da desigualdade em níveis mais elevados de renda, os autores avaliaram uma amostra de 71 países com dados referentes ao período de 1961 a 1992, incluindo nas estimaçóes um polinômio de terceiro grau em relação à 
renda per capita. Os resultados obtidos sinalizaram aumento da desigualdade em estágios maiores de desenvolvimento. Assim, a CK assumiria um formato de um “N”, e não de um "U-invertido".

List e Gallet (1999), fundamentados pelo argumento de Bishop et al. (1991), atribuíram a reversão da queda da desigualdade em níveis elevados de renda per capita à transição de uma economia manufatureira para uma economia baseada em atividades de serviços, fenômeno que ocorre em estágios mais avançados de desenvolvimento econômico. Assim como a migração da população de atividades agrícolas para industriais, a migração entre estas últimas e as atividades de serviços geraria aumento da desigualdade de renda, em função do diferencial de rendimentos entre os setores, principalmente no caso dos trabalhadores com maiores níveis de educação (ou de habilidades).

Katz e Murphy (1992), por sua vez, ao analisarem o caso dos Estados Unidos, atribuíram a elevação da desigualdade de renda ocorrida no país, a partir de meados da década de 1970, ao aumento da demanda por trabalhadores mais qualificados em função de diversos fatores, como mudanças tecnológicas, crescimento do comércio internacional e globalização. Glaeser (2005) questiona esse argumento, defendendo que tais fenômenos também são observados em outros países, mas não foram acompanhados por aumento significativo da desigualdade. Para o autor, aspectos políticos, como tributações, benefícios trabalhistas e políticas assistencialistas e redistributivas, também devem ser considerados.

De acordo com a revisão da literatura realizada até o momento, aspectos econômicos e políticos se complementam na explicação da CK, principalmente em função do impacto das políticas redistributivas sobre a desigualdade e da maior probabilidade de adoção de tais políticas em estágios mais avançados de desenvolvimento, nos quais os indivíduos tendem a ser mais educados (ou habilidosos), mais organizados e, consequentemente, conseguem exercer maior influência política. Contudo, os governantes (políticos), motivados pela maximização de oportunidades eleitorais, podem atender à população de maneira não igualitária, beneficiando alguns segmentos em detrimento de outros. Assim, políticas redistributivas seriam influenciadas pelas preferências e pela capacidade dos indivíduos de exercerem pressão sobre os governantes, mas também pelo interesse destes em atender às demandas da população, motivados pela maximização de oportunidades eleitorais.

Para finalizar essa discussão, é importante destacar que, além de aspectos 
econômicos e políticos, aspectos históricos e institucionais, específicos de cada localidade, justificariam a relação $\mathrm{CK}$, seja no formato de "U-invertido", seja no formato de "N" - conforme defendido por Piketty (2006). Um importante argumento utilizado é que as instituiçóes políticas influenciam a adoção de políticas redistributivas (Glaeser, 2005).

\section{3_Desigualdade de acesso: caracterização e seletividade hierárquica}

No presente estudo, serão analisados três serviços de saneamento ambiental:

(i) coleta de lixo;

(ii) coleta de esgoto; e

(iii) abastecimento de água.

Para cada um desses serviços, é considerada como indicador de desigualdade de acesso a diferença da cobertura entre os domicílios mais ricos e os domicílios mais pobres. Com base em informaçóes dos Censos Demográficos de 1991 e 2000, esse indicador foi construído da seguinte maneira: em cada município e em cada ano, os domicílios foram ranqueados em função da renda domiciliar mensal per capita, sendo calculadas as proporçóes de domicílios com acesso no quinto quintil de renda (mais ricos) e no primeiro quin- til de renda (mais pobres); após isso, obteve-se a diferença entre essas proporçóes - medida em pontos percentuais.

A literatura especializada aponta a rede geral, nos casos do esgoto e da água, e a coleta por serviços de limpeza, no caso do lixo, como as formas ideais de provisão dos serviços, uma vez que, em geral, modos alternativos dependem de soluções individuais que não levam em conta as externalidades negativas que podem ser geradas. Diante desses fatos, optou-se por considerar a existência de acesso domiciliar apenas se o abastecimento de água e a coleta de esgoto forem realizados por rede geral, e a coleta de lixo for feita por serviço de limpeza.

A Figura 1 apresenta a distribuição das desigualdades municipais de acesso aos serviços de saneamento ambiental, em 1991 e em 2000. Complementando a figura, a Tabela 1 mostra algumas estatísticas desses indicadores (médias, desvios padrão e variaçóes). Observa-se que as médias eram positivas nos três serviços e nos dois anos, ou seja, os acessos médios nos domicílios mais ricos eram maiores, e essa superioridade diminuía no período (redução das médias), o mesmo ocorrendo com as diferenças entre os indicadores municipais (redução dos desvios padrão). É interessante apontar que existiam poucos casos de municípios nos quais o acesso nos do- 
micílios mais pobres era maior do que o nos mais ricos - indicadores com valores negativos. Tais fatos sinalizam a existência de relação positiva entre a renda domiciliar per capita e o acesso.

Verifica-se, ainda na Figura 1 e na Tabela 1, que a coleta de esgoto apresentava, nos dois anos analisados, os menores indicadores municipais médios de desigualdade de acesso e maior concentração dos municípios em valores próximos de zero. Uma vez que esse serviço também possuía a menor cobertura municipal média (proporção de domicílios com acesso) e grande parcela dos municípios com ausência do serviço em todos os domicílios, a menor desigualdade se dava pelo baixo acesso tanto entre os mais pobres como entre os mais ricos. A distribuiçãao das coberturas municipais dos serviços, em 1991 e em 2000, pode ser observada na Figura 2. Na Tabela 2, são apresentadas as principais estatísticas dos indicadores municipais de cobertura (médias, desvios padrão e variações).

É possível observar, na Figura 2 e na Tabela 2, crescimento da cobertura municipal média dos três serviços no período, mas também elevação das diferenças de cobertura entre os municípios nos casos da coleta de lixo e, principalmente, da coleta de esgoto (aumento dos desvios padrão). Além disso, verifica-se que os três serviços encontravam-se, em 1991 e em 2000, em estágios distintos de consolidação da cobertura. Pode-se apontar o abastecimento de água como o serviço que possuía, nos dois anos, melhor situação, uma vez que apresentava as maiores coberturas municipais médias e as menores concentraçóes de municípios com ausência de acesso em todos os domicílios. ${ }^{4}$ Nesse sentido, a coleta de lixo apresentava situação intermediária, e a coleta de esgoto era o serviço em pior situação.

\footnotetext{
${ }^{4}$ Segundo o BNDES

(1998), a melhor situação do abastecimento de água deve-se, em grande parte, à alocação dos investimentos públicos ao longo do tempo, que teriam privilegiado esse serviço, em função da maior rentabilidade e da visibilidade política superior
}

e mais imediata. Esta última
pode decorrer, pelo menos
em parte, de uma preferência
maior dos próprios cidadãos
pelo serviço. Uma evidência
nesse sentido foi observada
no "Exame da Participação do
Setor Privado na Provisão dos
Serviços de Abastecimento
de Água e de Esgotamento

Sanitário no Brasil”, realizado pelo Ministério das Cidades. Ao entrevistar diversas famílias que passaram a ter acesso e a ser cobradas pelos serviços após um processo de desestatização, 27\% dos entrevistados disseram que preferiam estar conectados somente ao abastecimento

\author{
de água, e apenas $2 \%$ \\ responderam que preferiam \\ estar conectados somente \\ à coleta de esgoto - $64,8 \%$ \\ preferem os dois serviços; \\ 3,3\%, nenhum deles, e 2,9\% \\ não souberam responder ou \\ não quiseram opinar.
}


Figura 1_Brasil: distribuições dos indicadores municipais de desigualdade de acesso aos serviços de saneamento ambiental, 1991 e 2000
(a) Coleta de Lixo
(b) Coleta de Esgoto
(C) Abastecimento de Água
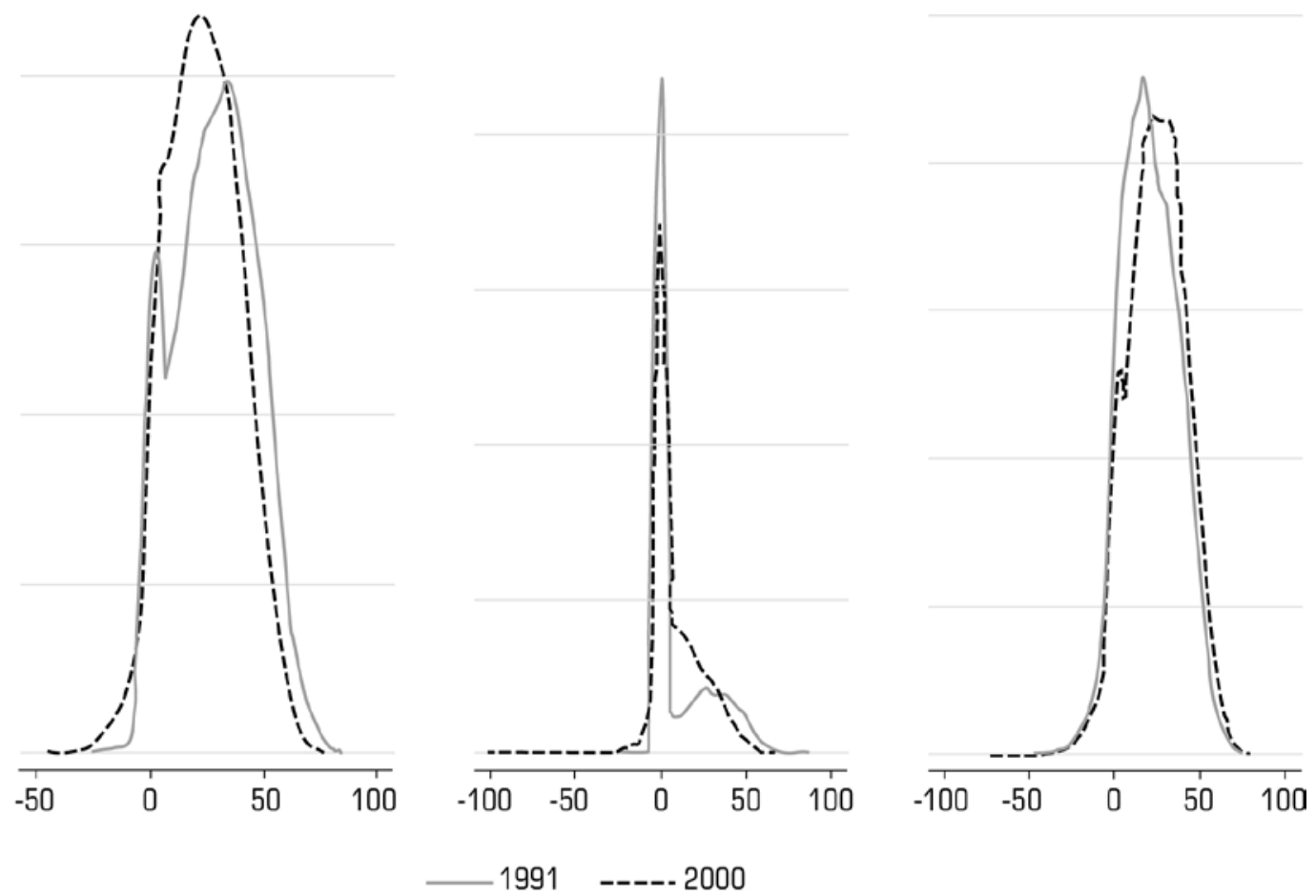

Fonte: IBGE, Censos Demográficos de 1991 e 2000. Elaboração própria.

Tabela 1_Brasil: indicadores municipais de desigualdade de acesso aos serviços de saneamento ambiental (médias, desvios padrão e variações), 1991 e 2000

\begin{tabular}{|c|c|c|c|c|c|c|}
\hline \multirow{2}{*}{ Serviços } & \multicolumn{3}{|c|}{ Média (pontos percentuais) } & \multicolumn{3}{|c|}{ Desvio padrão (pontos percentuais) } \\
\hline & 1991 & 2000 & $\Delta \% 91-00$ & 1991 & 2000 & $\Delta \% 91-00$ \\
\hline Coleta de Lixo & 28,63 & 23,17 & $-19,07$ & 17,95 & 16,32 & $-9,08$ \\
\hline Coleta de Esgoto & 10,47 & 9,90 & $-5,44$ & 17,05 & 14,27 & $-16,30$ \\
\hline Abastecimento de Água & 24,85 . & 21,05 . & $-15,29$ & 17,11 & 16,56 . & $-3,21$ \\
\hline
\end{tabular}

Fonte: IBGE, Censos Demográficos de 1991 e 2000. Elaboração própria. $\Delta \%$ 91-00: variação percentual de 1991 a 2000. 
Figura 2_Brasil: distribuições dos indicadores municipais de cobertura dos serviços de saneamento ambiental, 1991 e 2000

(a) Coleta de Lixo

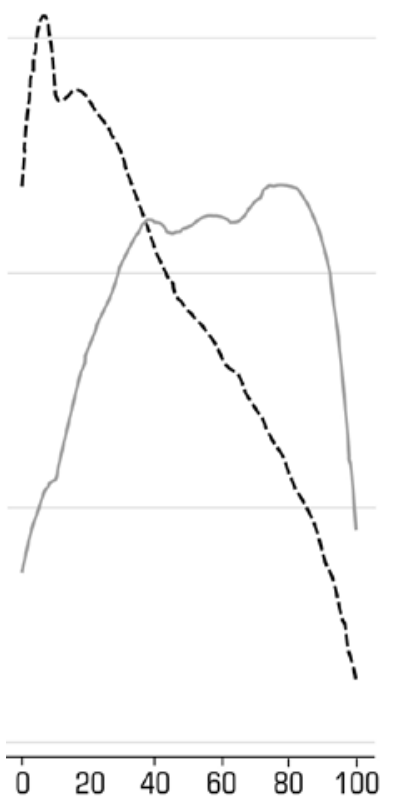

(b) Coleta de Esgoto

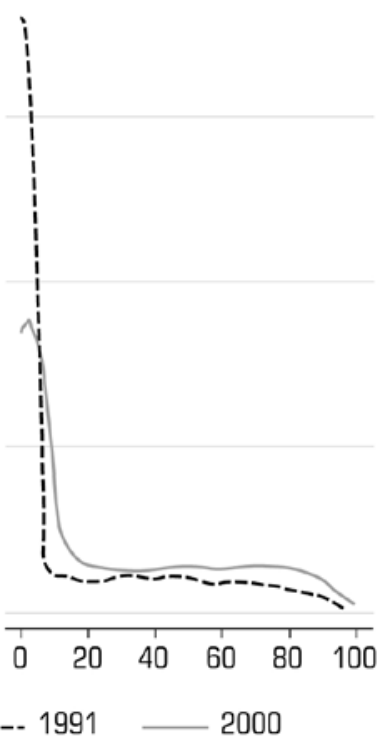

(C) Abastecimento de Água

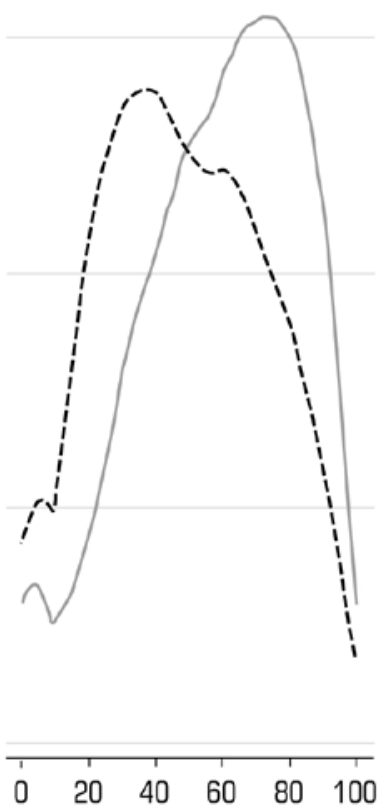

Fonte: IBGE, Censos Demográficos de 1991 e 2000. Elaboração própria.

De acordo com Rezende et al. (2007), para avaliar o acesso a serviços de saneamento ambiental, é necessário levar em conta a interação entre os condicionantes da demanda e da oferta desses. Pelo lado da oferta, deve-se considerar o que explicaria a presença das redes de água e de esgoto ou dos sistemas de coleta de lixo nos domicílios. Por se tratar de um setor em que a provisão pública é predominante, aspectos políticos tam- bém devem ser considerados. Pelo lado da demanda, deve-se analisar o que faria os domicílios, existindo a provisão dos serviços, optarem ou não pela adesão a eles.

Se o acesso é explicado por condicionantes da demanda e da oferta dos serviços, o mesmo pode ser dito em relação à desigualdade de acesso. Deve-se apontar, primeiramente, que esta pode decorrer da própria capacidade desigual dos domicílios 
Tabela 2_Brasil: indicadores municipais de cobertura dos serviços de saneamento ambiental (médias, desvios padrão e variações), 1991 e 2000

\begin{tabular}{|c|c|c|c|c|c|c|}
\hline \multirow{2}{*}{ Serviços } & \multicolumn{3}{|c|}{ Média (proporção dos domicílios) } & \multicolumn{3}{|c|}{ Desvio padrão (pontos percentuais) } \\
\hline & 1991 & 2000 & $\Delta \% 91-00$ & 1991 & 2000 & $\Delta \% 91-00$ \\
\hline Coleta de Lixo & 36,31 & 53,56 & 47,51 & 27,07 & 27,12 & 0,18 \\
\hline Coleta de Esgoto & 15,28 & 36,31 & 137,63 & 25,61 & 30,28 & 18,24 \\
\hline Abastecimento de Água & 47,26 & 58,35 . & 23,47 & 24,85 . & 24,12 . & $-2,94$ \\
\hline
\end{tabular}

Fonte: IBGE, Censos Demográficos de 1991 e 2000. Elaboraçấo própria. $\Delta \%$ 91-00: variação percentual de 1991 a 2000.

de pagarem pelos serviços. Tal argumento, contudo, não pode ser considerado como a única explicação para o problema, uma vez que os serviços não são cobrados em grande parte dos domicílios, e são adotados mecanismos de subsídios cruzados em diversas localidades. ${ }^{5}$

Assim, explicações complementares devem ser consideradas. Uma justificativa a ser destacada é a apresentada por Bichir (2009): os governantes, ao realizarem investimentos para a expansão e a melhora da infraestrutura urbana em determinadas áreas, valorizam os imóveis lá localizados. Isso pode fazer com que os indivíduos mais pobres náo consigam arcar com o consequente aumento dos aluguéis ou, no caso de serem proprietários de seus imóveis, sintam-se incentivados a vendê-los, deslocando-se para áreas periféricas desprovidas de serviços de saneamento ambiental.
É importante apontar que, mesmo se não forem cobradas tarifas, o simples custo de ligação às redes, no caso do abastecimentodeáguaeda coletadeesgoto, pode inviabilizar o acesso dos mais pobres aos serviços. Além disso, independentemente da capacidade de pagamento e da cobrança ou não pelos serviços, os indivíduos optam pelo acesso se forem capazes de apreciar os benefícios que podem ser gerados (Mendonça et al., 2004). Essa capacidade decorre de aspectos culturais e educacionais que, por serem relacionados à renda dos indivíduos, influenciam a desigualdade de acesso.

Rezende et al. (2007) encontraram evidências de uma relação positiva entre o acesso domiciliar e o nível educacional do chefe do domicílio. Os autores argumentam que maior educação pode tornar os indivíduos mais conscientes em relação a questóes ambientais e de saúde, deman-

\footnotetext{
${ }^{5}$ Segundo informaçóes da última Pesquisa Nacional de Saneamento Básico, realizada em 2000 pelo IBGE, naquele ano, o abastecimento de água não era cobrado em $19 \%$ dos distritos em que o serviço era ofertado. No caso da coleta de esgoto, não havia cobrança em $48 \%$ dos distritos com o serviço. Já no caso da limpeza urbana e/ou coleta de lixo, $54 \%$ dos municípios não cobravam pelo serviço.
} 
dando serviços adequados de saneamento ambiental e tentando influenciar as decisões dos governantes nesse sentido. Duas decorrências diretas do desenvolvimento econômico, apontadas na seção anterior, podem contribuir para isso.

A primeira é a elevaçáo da concentração populacional em áreas urbanas, que, ao reduzir a distância entre os indivíduos, aumenta a possibilidade de esses se organizarem e, consequentemente, de exercerem maior pressão política. Outra decorrência é o aumento da parcela da população com níveis mais elevados de educação e, em função disso, com influência política - considerando a hipótese de que existiria relação positiva entre a participação política e o nível educacional. Essas são possíveis justificativas para as tendências de aumento da cobertura à medida que a população, a taxa de urbanização e a renda per capita se elevam (Motta, 2004; Saiani, 2006).

As relações com a população e com a taxa de urbanização podem sinalizar ainda a existência de economias de escala e de densidade no setor, no sentido de que, quanto maior o número de beneficiários e mais eles estiverem concentrados, menor o custo de provisão dos serviços. No caso da população, a relação pode decorrer também do número de potenciais contribuintes, que viabilizaria a provisão em função do pagamento de tarifas e de tribu- tos. Seguindo essa linha de raciocínio, outra possível justificativa para a relação positiva entre a cobertura e a renda per capita seria a viabilidade econômica da provisão, uma vez que municípios mais desenvolvidos tendem a ter arrecadação tributária maior e, por consequência, mais recursos para a realização de investimentos.

O tamanho e a concentração da população, assim como o grau de desenvolvimento econômico dos municípios, são apontados pela literatura como possíveis determinantes da cobertura dos serviços. Contudo, por causa dos canais de propagação dos impactos, comentados nos parágrafos anteriores, tais variáveis também poderiam influenciar a desigualdade de acesso. Não há, contudo, nenhum trabalho que tenha avaliado essa possibilidade.

É importante apontar que a desigualdade de acesso aos serviços poderia ser, pelo menos em parte, uma decorrência da existência de uma Seletividade Hierárquica das Politicas (SHP) voltadas para o setor. De acordo com essa hipótese, algumas políticas seriam adotadas para beneficiar prioritariamente, e com melhor qualidade, os grupos sociais mais ricos e escolarizados; posteriormente, beneficiariam os demais cidadãos (Marques, 2000).

A justificativa sociológica para a SHP fundamenta-se na cultura técnica da burocracia, que efetivamente implanta as políti- 


\section{Figura 3_Brasil: relaçóes (ajustadas) entre os indicadores municipais de desigualdade de acesso e de cobertura dos serviços de saneamento ambiental, 1991 e 2000}

(a) Coleta de Lixo

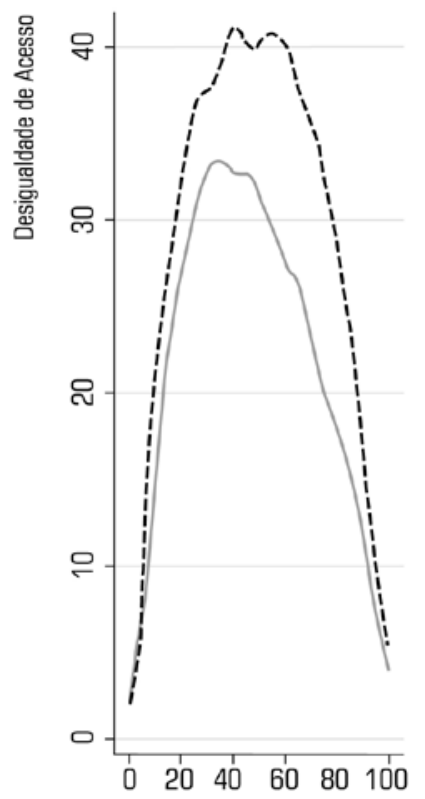

(b) Coleta de Esgoto

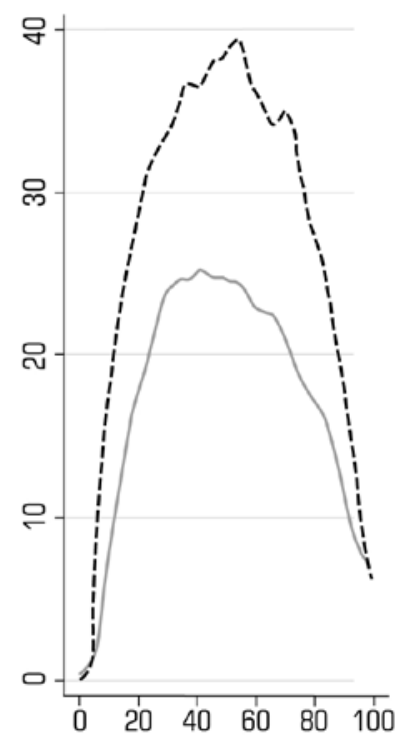

(C) Abastecimento de Água

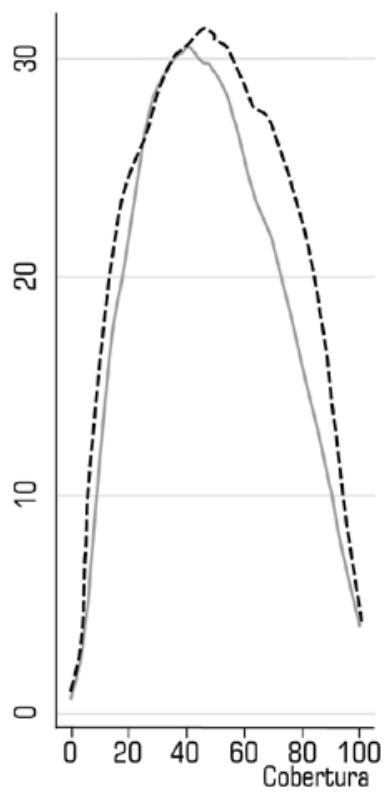

\section{$1991-2000$}

Fonte: IBGE, Censos Demográficos de 1991 e 2000. Elaboração própria.

cas e, em determinados setores, pode entender que as prioridades estatais devem seguir a estrutura social (Marques; Bichir, 2001). Pode-se pensar ainda que os governantes teriam um incentivo a beneficiar prioritariamente os mais ricos e educados em função de maior pressão política e, consequentemente, de potenciais resultados eleitorais gerados por essa preferência; posteriormente, expandiriam os benefícios aos mais po- bres. No caso de serviços em que há a possibilidade de se cobrar a provisão, como os de saneamento ambiental, a viabilidade econômica inicial do negócio seria outro fator que poderia influenciar a prioridade dada aos mais ricos.

$\mathrm{Na}$ ausência de trabalhos que formalizaram uma maneira de avaliar a existência da SHP para os serviços de saneamento ambiental, ${ }^{6}$ no presente estudo é
${ }^{6} \mathrm{O}$ único estudo (6) estudo encontrado que testou a validade dessa hipótese para os serviços de saneamento ambiental foi o de Bichir (2009). O autor, contudo, utilizou análises multivariadas e restringiu sua análise ao município de São Paulo, comparando as políticas voltadas para a área central com as políticas voltadas para a periferia. 
proposto que essa é caracterizada se a relação entre o indicador municipal de desigualdade de acesso e a cobertura municipal do respectivo serviço assumir o formato de um "U-invertido", não necessariamente simétrico. Ou seja, se no início da consolidação do serviço, os mais ricos forem privilegiados, aumentando a desigualdade de acesso; mas, uma vez atingido certo grau de cobertura, o acesso for expandido para os mais pobres, ocorrerá redução da desigualdade. Algumas estimaçóes serão realizadas mais adiante para testar essa hipótese, mas evidências favoráveis já podem ser observadas na Figura 3, que apresenta gráficos das relaçôes entre os indicadores municipais de desigualdade de acesso e as coberturas dos serviços, em 1991 e $2000 .^{7}$

\section{Estratégias de estimação}

Em diversos trabalhos, a hipótese da Curva de Kuznets (CK) foi testada, com da-

${ }^{7}$ Os gráficos são ajustados a partir de uma regressão polinomial não paramétrica com os indicadores municipais de desigualdade de acesso a cada serviço, como variáveis dependentes, e os respectivos indicadores municipais de cobertura, como variáveis explicativas.

Utiliza-se, para isso, o método de Kernel-Weighted Local Polynomial Regression. Para mais detalhes sobre esse método de estimação, ver, entre outros: Jones et al. (1994), Ruppert e Wand (1994) e Aerts e Claeskens (1997). dos em cross-section, por meio de estimações paramétricas baseadas na equação (1), que considera um polinômio de segundo grau em relação à medida de desenvolvimento econômico.

$Z_{i}=\propto_{0}+\propto_{1} D_{i}+\propto_{2} D_{i}^{2}+\varepsilon_{i}$

sendo $Z_{i}$ uma medida de desigualdade de renda da localidade $i$; $D_{i}$ uma medida de desenvolvimento econômico da localidade $i$ - a renda per capita é a mais utilizada -, e $\varepsilon_{i}$ o erro aleatório. Para que a hipótese seja corroborada, ou seja, para que a relação entre a desigualdade de renda e o desenvolvimento econômico apresente o formato de um "U-invertido", os coeficientes $\propto_{1}$ e $\propto_{2}$, além de significativos, devem respeitar as seguintes condições de sinais: $\propto_{1}>0$ e $\propto_{2}<0$.

Fields e Jakubson (1994) contestam o uso de dados em cross-section para testar a existência da $\mathrm{CK}$, em função de essa relação decorrer de processos dinâmicos de transformaçóes na economia - conforme apontado na primeira seçáo -, o que justifica a utilizaçáo de dados em painel. Além disso, métodos em painel podem diminuir possíveis vieses decorrentes de características específicas de cada localidade, que induziriam trajetórias únicas e que não são controladas nas estimaçóes seccionais (Bagolin et al., 2004). 
Entre as abordagens com dados em painel, a de efeitos fixos (estimador Within ${ }^{8}$ ) é a mais adequada para testar a validade da $\mathrm{CK}$, uma vez que permite estimar se as desigualdades de renda de diferentes localidades seguem as mesmas trajetórias ao longo do desenvolvimento econômico, mesmo que com interceptos distintos. A vantagem da abordagem decorre da possibilidade de se corrigir o potencial viés associado à correlação entre variáveis omitidas, fixas no tempo, e os regressores incluídos no modelo, assim como o efeito comum às unidades seccionais, mas que variam ao longo do tempo.

O teste da hipótese da CK, pelo método de efeitos fixos, é feito por meio da estimação de modelos baseados na equação (2) - a hipótese continua a ser corroborada com $\propto_{1}>0$ e $\propto_{2}<0$, quando os dois coeficientes são significativos.

$$
\begin{aligned}
Z_{i t}=\propto_{0}+\propto_{1} D_{i t}+ & \propto_{2} D_{i t}^{2}+ \\
& +u_{i}+T_{\mathrm{t}}+\varepsilon_{i t}
\end{aligned}
$$

sendo $Z_{i t}$ uma medida de desigualdade de renda da localidade $i$ no período $t ; \mathrm{D}_{\mathrm{it}}$ uma medida de desenvolvimento econômico da localidade $i$ no período $t ; u_{i}$ um conjunto de características da localidade $i$ constantes no tempo (efeitos fixos); $T_{\mathrm{t}} \mathrm{um}$ conjunto de características constantes entre as localidades, mas que variam no tempo - geralmente, são utilizadas dummies de períodos - e $\varepsilon_{i t}$ o erro aleatório.

As equações (1) e (2) mostram formas de testar se a relação entre a desigualdade de renda e o desenvolvimento econômico assume o formato de um "U-invertido". Já para testar, por efeitos fixos, a hipótese da CK no formato de um "N", inclui-se em (2) um polinômio de terceiro grau em relação à medida de desenvolvimento econômico - conforme a equação (3). A hipótese é corroborada quando:

(i) os coeficientes $\propto_{1}, \propto_{2}$ e $\propto_{3}$ forem significativos;

\footnotetext{
${ }^{8} \mathrm{O}$ estimador Within é apontado pela literatura como consistente para controlar, em estimaçōes com dados em painel, os efeitos de características das unidades de análise (no caso, localidades) que não variam ao longo do tempo (efeitos fixos). Considerando como exemplo o modelo
}

\author{
$Y_{i t}=u_{i}+T_{\mathrm{t}}+\beta X_{i t}+\varepsilon_{i t}$, as \\ estimações são realizadas \\ por Mínimos Quadrados \\ Ordinários, e as variáveis \\ dependentes $\left(Y_{i t}\right) \mathrm{e}$ \\ independentes $\left(X_{i t}\right)$, de \\ cada localidade $i$ e em cada \\ período $t$, são transformadas \\ em desvios em relaçáo às suas \\ respectivas médias \\ $\left(\bar{Y}_{i}\right.$ e $\left.\bar{X}_{i}\right)$. Ou seja, o modelo é
}

estimado da seguinte maneira: $Y_{i t}-\bar{Y}_{i}=\left(T_{t}-\bar{T}\right)+\beta\left(X_{i t}-\bar{X}_{i}\right)+\left(\varepsilon_{i t}-\varepsilon_{i}\right)$

. Os termos $u_{i}, T_{\mathrm{t}}$ e $\varepsilon_{i t}$ representam, respectivamente, o conjunto de características da localidade $i$ constantes no tempo (efeitos fixos), o conjunto de características constantes entre as localidades, mas que variam ao longo do tempo (dummies de períodos) e o erro aleatório. Para uma discussão mais aprofundada sobre o estimador Within e, especificamente, como os desvios em relação às médias controlam os efeitos fixos, ver, por exemplo: Greene (1997), Baltagi (2001), Wooldridge (2002) e Angrist e Pischke (2009). 
(ii) $\propto_{1}>0$;

(iii) $\propto_{2}<0$ e (iv) $\propto_{3}>0$. Caso $\propto_{1}>0$ e $\propto_{2}<0$, mas $\propto_{3}$ é não significativo ou menor do que zero, a relação assume o formato tradicional de um "U-invertido".

$$
Z_{i t}=\propto_{0}+\propto_{1} D_{i t}+\propto_{2} D_{i t}^{2}+\propto_{3} D_{i t}^{3}+u_{i}+T_{\mathrm{t}}+\varepsilon_{i t}
$$

É importante destacar que o polinômio de segundo grau, originalmente proposto por Ahluwalia (1976), é utilizado na maioria dos trabalhos que testaram parametricamente a hipótese da CK. Em trabalhos posteriores, observou-se que, para algumas medidas, outras formas funcionais são mais adequadas. Anand e Kanbur (1993) derivaram as especificaçóes que se ajustam melhor a seis medidas de desigualdade. Com base nesses trabalhos, pode-se apontar a forma polinomial como adequada para os indicadores de desigualdade utilizados no presente estudo - que seráo comentados mais adiante. Além disso, essa forma é coerente com a proposta de List e Gallet (1999), representada pela equação (3), para o teste da hipótese da relação entre desigualdade de renda e desenvolvimento econômico no formato de um " $N$ ".

A validação da CK apenas por meio da estimação de modelos baseados nas equaçóes (1), (2) e (3) é questionada na li- teratura. Jha (1996), por exemplo, aponta que alguns estudos encontraram evidências favoráveis ao considerar conjuntamente países desenvolvidos e em desenvolvimento. Contudo, ao analisarem apenas países em desenvolvimento, as evidências não foram tão favoráveis. Esse fato pode sinalizar que os resultados encontrados para a amostra total poderiam refletir outras diferenças entre os países, e não apenas a relação entre desigualdade de renda e desenvolvimento econômico.

Para lidar com esse problema, pode-se adotar a sugestão dada por Ahluwalia (1976) de incluir, nas estimaçôes, variáveis de controle que refletem características distintas das localidades e que podem influenciar a desigualdade de renda. Assim, devem ser estimados modelos baseados na equação (4), que incorpora um conjunto de características observáveis (controles) da localidade $i$ no período $t\left(W_{i t}\right)$ - o que foi feito em diversos estudos. A hipótese da CK no formato de um "N" continua a ser corroborada quando: (i) $\propto_{1}$, $\propto_{2}$ e $\propto_{3}$ são significativos; (ii) $\propto_{1}>0$; (iii) $\propto_{2}<0$ e (iv) $\propto_{3}>0$. Por outro lado, a relação ainda assume o formato de um "U-invertido" quando $\propto_{1}>0, \propto_{2}<0$ e $\propto_{3}<0$ (ou não significativo).

$$
Z_{i t}=\propto_{0}+\propto_{1} D_{i t}+\propto_{2} D_{i t}^{2}+\propto_{3} D_{i t}^{3}+\propto_{4} W_{i t}+u_{i}+T_{\mathrm{t}}+\varepsilon_{i t}
$$


Barros e Gomes (2008) testaram parametricamente, com dados de 1991 e de 2000, a hipótese da CK para os municípios brasileiros. Para isso, foram estimados modelos baseados na equação (3) e com formas funcionais alternativas baseadas em Anand e Kanbur (1993). Os índices de Gini e L de Theil foram usados como medidas de desigualdade de renda; já a renda municipal per capita e a razão entre a população urbana e a população total foram usadas como medidas de desenvolvimento econômico. As evidências encontradas foram ambíguas, sendo a hipótese, nos dois formatos ("U-invertido" ou "N"), corroborada em algumas especificações, e não em outras. Ou seja, assim como foi observado em estudos para diversas localidades, no caso dos municípios brasileiros, as estimativas são sensíveis à mudança da medida de desigualdade e à forma funcional do modelo. Constatou-se ainda um baixo poder explicativo dos modelos (estatística $\mathrm{R}^{2}$ ), o que, segundo os autores, sugere uma capacidade limitada da CK para explicar a desigualdade de renda entre os municípios brasileiros.

Outros estudos testaram parametricamente a hipótese da CK, no formato de um "U-invertido", para amostras menores de municípios brasileiros (por Estados ou regióes geográficas). ${ }^{9}$ De maneira geral, os resultados obtidos não rejeitam a hipótese, mas também indicam capacidade limitada dessa para explicar a desigualdade de renda. Figueiredo et al. (2011), por sua vez, encontraram evidências de uma relação não linear entre a desigualdade de renda (índice de Gini) e o desenvolvimento econômico (renda per capita) considerando informaçóes referentes a 1991 e 2000 de todos os municípios brasileiros. Tais evidências, favoráveis à $\mathrm{CK}$ (no formato de "U-invertido" ou de um "N"), foram obtidas por estimações não paramétricas e paramétricas baseadas na equação (3) e na forma funcional defendida por Anand e Kanbur (1993) como a mais adequada para o índice de Gini.

Embora enfatize mais a questão do acesso a serviços de saneamento ambiental, o presente estudo também contribuirá para o debate sobre a existência ou não de uma CK (e do formato dessa relaçáo) para o caso da desigualdade de renda entre os municípios brasileiros. Deve-se apontar, primeiramente, que serão realizadas estimaçóes baseadas na equaçáo (3), assim como foi feito por Barros e Gomes (2008) e Figueiredo et al. (2011), mas também baseadas na equação (4), que considera um conjunto de características municipais $\left(W_{i t}\right)$ que podem explicar a desigualdade. Além disso, é utilizada como proxy para a desigualdade de renda a diferença entre a proporção da renda do muni-

\footnotetext{
${ }^{9}$ Ver: Bêrni et al. (2002),

Bagolin et al. (2004),

Jacinto e Tejada (2004) e Salvato et al. (2006).
} 
${ }^{10}$ Em relação aos municípios brasileiros, não foram encontrados estudos que adotaram a mesma proxy para a desigualdade e que consideraram um conjunto amplo de variáveis de controle que também podem explicá-la. cípio apropriada pelo quintil mais rico da distribuição de indivíduos, segundo a renda domiciliar per capita, e a proporção da renda apropriada pelos indivíduos pertencentes ao quintil mais pobre da distribuição. ${ }^{10}$

A escolha desse indicador deve-se a dois dos objetivos do presente estudo: (i) testar se a capacidade desigual de pagamento dos domicílios determina a desigualdade de acesso a serviços de saneamento ambiental e (ii) avaliar se existe uma relação do tipo da CK, seja no formato de um "U-invertido", seja no formato de um "N", entre a desigualdade de acesso e o desenvolvimento econômico. Como serão utilizados os indicadores de desigualdade de acesso municipais apresentados na seção anterior, que consideram a diferença da cobertura dos serviços nos domicílios do $5^{\circ}$ quintil de renda (mais ricos) e nos domicílios do $1^{\circ}$ quintil (mais pobres), optou-se por uma medida de desigualdade de renda que também leve em conta a diferença entre os $20 \%$ mais ricos e os $20 \%$ mais pobres.

Assim como nos estudos anteriores, é utilizada como medida de desenvolvi- mento econômico $\left(D_{i t}\right)$ a renda municipal per capita (em valores de 2000), calculada pela razão entre o somatório da renda familiar per capita de todos os domicílios e o número total de domicílios no município. A renda familiar per capita é a razão entre a soma da renda mensal de todos os indivíduos residentes no domicílio e o número total de indivíduos.

Para atingir os objetivos propostos, serão estimados ainda modelos baseados nas equações (5) e (6), que fazem algumas adaptaçóes à equação (4). Primeiramente, deve-se apontar que os indicadores de desigualdade de acesso à coleta de lixo, à coleta de esgoto e ao abastecimento de água, de cada município $i$ no ano $t$, são as variáveis dependentes $\left(S_{i t}\right)$ - esses indicadores foram apresentados na seção anterior. Além disso, a desigualdade de renda do município $i$ no ano $t\left(Z_{i t}\right)$ é incorporada como variável explicativa na equação (6), o que permite avaliar, de forma mais robusta, se as relaçóes encontradas são consequência apenas da distribuição desigual da renda ou se dependem de outros fatores, como aspectos políticos.

$$
\begin{aligned}
& S_{i t}=\propto_{0}+\propto_{1} D_{i t}+\propto_{2} D_{i t}^{2}+\propto_{3} D_{i t}^{3}+\propto_{4} W_{i t}+u_{i}+T_{\mathrm{t}}+\varepsilon_{i t} \\
& S_{i t}=\propto_{0}+\propto_{1} D_{i t}+\propto_{2} D_{i t}^{2}+\propto_{3} D_{i t}^{3}+\propto_{4} W_{i t}+\propto_{5} Z_{i t}+u_{i}+T_{\mathrm{t}}+\varepsilon_{i t}
\end{aligned}
$$


Os resultados mostrarão evidências de que as relaçóes entre as desigualdades de acesso aos serviços de saneamento ambiental e o desenvolvimento econômico possuem um formato de um " $N$ " se $\propto_{1}$, $\propto_{2}$ e $\propto_{3}$ forem significativos, sendo $\propto_{1}>0, \propto_{2}<0$ e $\propto_{3}>0$. Se $\propto_{1}>0$, $\propto_{2}<0$ e $\propto_{3}<0$ ou não significativo, as relaçóes assumem o formato de um "U-invertido".

As variáveis de controle utilizadas nas estimações $\left(W_{i t}\right)$, descritas no Quadro 1 , representam um conjunto de características observáveis dos municípios que poderiam influenciar a desigualdade de renda e a desigualdade de acesso aos serviços de saneamento. A adoção de tais controles é justificada, em grande parte, pela revisão da literatura realizada nas duas primeiras seçóes, que mostraram possíveis determinantes, além do próprio acesso, da relação CK - são os casos das variáveis taxa de urbanização, densidade demográfica, taxa de analfabetismo, população, setor de serviços, taxa de fecundidade e náo branco.

$\mathrm{Na}$ ausência de teoria ou estudos prévios, foram escolhidas algumas características municipais que, valendo-se da literatura de outros serviços públicos, supostamente podem influenciar o acesso a saneamento ambiental. As variáveis energia e televisão, telefone, carro e geladeira são utilizadas como proxies de riqueza dos mu- nicípios. As variáveis abaixo de 18 anos e acima de 65 anos foram incluídas com o intuito de captar características distintas da demanda, uma vez que indivíduos nessas faixas etárias necessitam de cuidados especiais, o que poderia resultar em maiores pressóes sociais por melhoras e ampliação dos serviços. A variável área, por sua vez, é utilizada para captar diferenças de custos em função do tamanho do território e o potencial efeito do desmembramento de um distrito.

Além das variáveis observáveis, são consideradas:

(i) características não observáveis $\left(\mathcal{u}_{i}\right)$, diferentes entre os municípios, mas constantes ao longo do tempo (efeitos fixos) - conforme apontado nas primeiras seções, aspectos históricos, institucionais e culturais específicos de cada município, que não variam ao longo do tempo, também poderiam influenciar a desigualdade de renda e a desigualdade de acesso aos serviços -; e

(ii) uma dummy de ano $\left(T_{\mathrm{t}}\right)$, igual a zero em 1991 e um em 2000, que captaria o efeito de características não observáveis constantes entre os municípios, mas que variam ao longo do tempo - e que mostraria tendência comum de variação dos indicadores no período. 
Um sério problema de corroborar a hipótese da CK por meio de estimações que consideram países distintos é a relativa incomparabilidade dos dados, uma vez que esses são obtidos em diferentes fontes de informação (Thornton, 2001). De acordo com Barros e Gomes (2008), os resultados obtidos em estudos internacionais podem sofrer a influência de erros de medida (viés), que decorreriam de diferenças nos questionários utilizados para a coleta das informaçóes, assim como de fatores que possam interferir na aferição dos indicadores. Desse modo, uma vantagem do presente estudo é considerar os municípios brasileiros como unidade de análise, $o$ que reduz o viés de erro de medida, já que os dados são obtidos, de maneira geral, na mesma fonte de informaçóes (IBGE).

Outro objetivo do estudo é testar a existência de uma Seletividade Hierárquica das Politicas (SHP), no caso dos serviços de saneamento ambiental. De acordo com essa hipótese, apontada na terceira (segunda) seção, as políticas públicas seriam adotadas prioritariamente - e com

\section{Quadro 1_Descrição das variáveis de controles (indicadores municipais)}

\begin{tabular}{|c|c|}
\hline & \\
\hline laxa de Urbanızaçao & Kazao entre a populaçao residente em areas urbanas e a populaçao total \\
\hline Densidade Demográfica & Razão entre a população total e a área total \\
\hline População & População total \\
\hline Taxa de Analfabetismo & Percentual de pessoas de 25 ou mais anos de idade que não sabem ler nem escrever \\
\hline Área & Área total \\
\hline Setor de Serviços & Razão entre o número de empregados no setor de serviços e o total de funcionários \\
\hline Taxa de Fecundidade & Número médio de filhos que uma mulher teria ao terminar o período reprodutivo \\
\hline Abaixo de 18 Anos & Razão entre a população abaixo de 18 anos e a população total \\
\hline Acima de 65 Anos & Razão entre a população acima de 65 anos e a populaçáo total \\
\hline Não Branco & Razão entre a população não branca e a população total \\
\hline Energia e Televisão & $\begin{array}{l}\text { Percentual de pessoas que vivem em domicílios com energia elétrica e } \\
\text { com aparelho de televisáo em cores ou em preto e branco }\end{array}$ \\
\hline Carro & $\begin{array}{l}\text { Percentual de pessoas que vivem em domicílios com automóvel de passeio ou } \\
\text { com veículo utilitário }\end{array}$ \\
\hline Telefone & $\begin{array}{l}\text { Percentual de pessoas que vivem em domicílios com linha convencional de } \\
\text { telefone instalada, própria, alugada ou ramal }\end{array}$ \\
\hline Geladeira & Percentual de pessoas que vivem em domicílios com geladeira ou freezer \\
\hline
\end{tabular}


melhor qualidade - para atender os mais ricos e, posteriormente, voltariam-se para os mais pobres. Para o caso dos serviços de saneamento ambiental, a hipótese pode ser entendida da seguinte maneira: no início da consolidação da cobertura, a desigualdade de acesso aumentaria, mas passaria a reduzir a partir de certo nível. Assim, existiria uma relação no formato de um "U-invertido" entre a desigualdade de acesso e a cobertura dos serviços.

Após busca detalhada na literatura, não foram encontrados trabalhos que formalizaram uma maneira de testar a hipótese da SHP. Dessa forma, este estudo se propóe a testá-la estimando modelos baseados nas equaçóes (7) e (8) - nesta última, as hipóteses da CK e da SHP são testadas conjuntamente. $\mathrm{O}$ método mais adequado, nesse caso, também é o de efeitos fixos, por permitir estimar se as desigualdades de acesso de diferentes municípios, mesmo que, com interceptos distintos, seguem trajetória semelhante ao longo da consolidação da cobertura do serviço.

Os índices de desigualdade de acesso aos serviços analisados, do município $i$ no ano $t\left(S_{i t}\right)$, são as variáveis dependentes. Além dos regressores também utilizados para o teste da CK, é considerado um polinômio de segundo grau em relação à cobertura do respectivo serviço do muni- cípio $i$ no ano $t\left(A_{i t}\right)$. A hipótese da SHP será corroborada, ou seja, os resultados mostrarão evidências de uma relação no formato de um "U-invertido" entre a desigualdade de acesso e a cobertura dos serviços, se os coeficientes $\propto_{6}$ e $\propto_{7}$ forem significativos, sendo $\propto_{6}>0$ e $\propto_{7}<0$.

$$
\begin{array}{r}
S_{i t}=\propto_{0}+\propto_{4} W_{i t}+\propto_{5} Z_{i t}+\propto_{6} A_{i t}+\propto_{7} A_{i t}^{2}+u_{i}+T_{\mathrm{t}}+\varepsilon_{i t} \\
S_{i t}=\propto_{0}+\propto_{1} D_{i t}+\propto_{2} D_{i t}^{2}+\propto_{3} D_{i t}^{3}+\propto_{4} W_{i t}+ \\
+\propto_{5} Z_{i t}+\propto_{6} A_{i t}+\propto_{7} A_{i t}^{2}+u_{i}+T_{\mathrm{t}}+\varepsilon_{i t}
\end{array}
$$

Portanto, serão estimados, para o caso da desigualdade de renda, modelos baseados nas equaçóes (3) e (4) - denominados, de agora em diante, como especificaçóes I e II, respectivamente. Já para o caso das desigualdades de acesso, os modelos estimados serão baseados nas equações (5), (6), (7) e (8) - denominados, a partir de agora, como especificaçóes III, IV, V e VI, respectivamente. Conforme já apontado, será utilizado o método de efeitos fixos, sendo reportado o resultado do teste de Hausman para avaliar a melhor adequação dessa abordagem em comparaçáo a de efeitos aleatórios. ${ }^{11}$

As variáveis de controle $\left(W_{i t}\right)$ e a renda municipal per capita $\left(D_{i t}\right)$ são utilizadas na forma logarítmica, evitando-se

\footnotetext{
${ }^{11}$ Para mais detalhes sobre a abordagem de efeitos aleatórios, ver, por exemplo: Greene (1997), Baltagi (2001), Wooldridge (2002) e Angrist e Pischke (2009).
} 
casos em que os coeficientes têm muitas casas decimais em função da grande variação dessas. Assim, a interpretação dos coeficientes deve ser feita da seguinte maneira: uma variação de $1 \%$ em X está associada a uma variação de $\mathrm{Y}$ pontos percentuais na variável dependente. Como os indicadores municipais de desigualdade de renda $\left(Z_{i t}\right)$ e de desigualdade de acesso $\left(S_{i t}\right)$ - variáveis dependentes -, assim como os indicadores municipais de cobertura $\left(A_{i t}\right)$ - variáveis explicativas -, são iguais a zero em alguns municípios, optou-se por não utilizá-los na forma logarítmica, visto que isso poderia causar a perda de muitas observaçóes.

Por último, é importante destacar que os modelos também serão estimados retirando da amostra os municípios que, em 2000, possuíam prestadores privados. Ou seja, os modelos serão estimados apenas para os municípios que possuíam prestadores públicos nos dois anos analisados (1991 e 2000). Isso será feito para a coleta de esgoto e para o abastecimento de água - no caso da coleta de lixo, não há informaçóes que permitam essa desagregação. Dessa forma, será possível testar a robustez dos resultados, desconsiderando potenciais efeitos da desestatização sobre os resultados - esta poderia reduzir o acesso dos mais pobres em função de aumentos de tarifas, baixa tolerância à inadimplência, redução de subsídios cruzados e investimentos em áreas mais lucrativas (Galiani et al., 2005).

\section{5 (4)_Análise dos resultados}

A análise a ser realizada na presente seção focará os resultados que permitem validar ou não a hipótese da CK para o caso da desigualdade de renda e da desigualdade de acesso a serviços de saneamento ambiental nos municípios brasileiros, assim como a hipótese da SHP para esses serviços. Por causa da menor importância para a discussão, os resultados para alguns controles não serão reportados. De maneira geral, esses estão de acordo com o previsto pelas análises das seçôes anteriores. Conforme também era esperado, o teste de Hausman apontou, em todas as estimações, a melhor adequação do método de efeitos fixos.

A Tabela 3 apresenta os resultados das estimaçóes considerando a amostra total de municípios. Os resultados das especificaçóes I e II, que testam a validade da CK para o caso da proxy de desigualdade de renda adotada, sinalizam que a relação assume o formato de um " $N$ ", o que se observa sem e com a inclusáo de variáveis de controle. Isso porque os coeficientes do polinômio de terceiro grau em relação à renda municipal per capita são 
significativos e respeitam a regra de sinais apresentada anteriormente:

(i) positivo para a variável em nível;

(ii) negativo para a variável ao quadrado; e

(iii) positivo para a variável ao cubo. Contudo, assim como em estudos anteriores, apontados na seção anterior, verifica-se capacidade limitada da CK para explicar a desigualdade de renda entre os municípios brasileiros: na especificação I, a estatística $\mathrm{R}^{2}$ é igual a apenas 0,006 ; a incorporação de controles (especificação II) aumenta o valor da estatística, mas essa é igual a somente 0,080 .

Observa-se ainda que a taxa de urbanização possui impacto negativo sobre a desigualdade de renda, o que sugere que os municípios brasileiros têm desenvolvimento econômico médio de modo que um aumento da urbanização gera melhor distribuição de renda. Na primeira seção, foram comentadas possíveis justificativas para a relação encontrada entre a desigualdade e a urbanização.

Além disso, os resultados mostram impactos positivos da taxa de analfabetismo, da população e da densidade demográfica sobre a desigualdade de renda. $\mathrm{Ou}$ seja, quanto maior o número de analfabetos, pior a distribuição da renda da população, o que pode ser explicado tanto pelo diferencial de rendimentos entre os indivíduos alfabetizados e não alfabetizados como pela relaçáo entre o nível educacional e a participação política apontada anteriormente, que influenciaria a adoção de políticas redistributivas. Uma maior população, por outro lado, pode dificultar a adoção de tais políticas, pelo simples fato de o público-alvo ser maior. As relaçóes com a população e a densidade demográfica também podem refletir o fato de os grandes municípios tenderem a possuir concentração maior de indivíduos de baixa renda.

Conforme apontado na quarta seção, para que os indicadores municipais de desigualdade de acesso apresentem relaçóes do tipo da CK, os coeficientes da renda municipal per capita em nível e ao quadrado, além de significativos, devem ser positivos e negativos, respectivamente. Se os coeficientes dessa variável ao cubo forem significativos e positivos, as relações assumem o formato de um "N"; caso sejam significativos e negativos ou não significativos, as relaçóes assumem o formato de um "U-invertido”. Quaisquer outras combinaçôes de coeficientes sinalizam a inexistência de tais relações.

Avaliando os resultados das especificações III e IV, observa-se que esses indicam apenas o abastecimento de água apresentando relação do tipo da CK, no formato de um "N". Ou seja, a desigual- 
dade de acesso a esse serviço aumenta em estágios inferiores de desenvolvimento econômico, passando a se reduzir a partir de certo ponto, mas voltando a aumentar em estágios avançados. $\mathrm{Na}$ coleta de lixo e na coleta de esgoto, verifica-se que as desigualdades de acesso apresentam a seguinte tendência ao longo do desenvolvimento: redução no início, seguida por um aumento e, posteriormente, por uma nova reduçáo.

Considerando que os três serviços apresentam situaçóes diferentes em relação à consolidação da cobertura, conforme foi constatado na terceira seção, esses resultados podem mostrar que, em etapas iniciais da provisão, a desigualdade de acesso diminui à medida que o município se desenvolve - o que se verifica nos casos da coleta de lixo e da coleta de esgoto, que apresentam, em comparação ao abastecimento de água, menores coberturas médias e maior concentração de municípios com baixo acesso. A partir de certo nível de cobertura, a desigualdade de acesso e o desenvolvimento econômico passariam a apresentar relação do tipo da CK. No caso da água, esta já assume o formato de um "N", mostrando possível tendência dos outros serviços à medida que as coberturas se consolidarem.

A inclusão da desigualdade de renda como variável explicativa (especificação IV) não altera os resultados. Observa-se que essa variável relaciona-se significativa e positivamente com as desigualdades de acesso à coleta de lixo e ao abastecimento de água, mas não afeta significativamente a desigualdade de acesso à coleta de esgoto - o que pode ser explicado, pelo menos parcialmente, pelo fato de a provisão desse serviço ser a menos cobrada (PNSB, 2000). A taxa de analfabetismo, por sua vez, relaciona-se, nos três serviços e nas especificaçóes III e IV, significativa e positivamente com a desigualdade de acesso. Relaçóes semelhantes foram encontradas para a população, mas apenas para a coleta de lixo, nas duas especificaçóes, e para o abastecimento de água, na especificação III. As relaçóes com a taxa de urbanização não foram significativas em nenhuma das especificaçóes, nos três serviços. Já as relações com a densidade demográfica foram significativas nos três serviços, sendo positivas na coleta de lixo e no abastecimento de água, e negativas na coleta de esgoto.

As especificaçóes V e VI incorporam o teste da hipótese da SHP, que pressupóe a existência de uma relaçáo no formato de um "U-invertido" entre a desigualdade de acesso e a cobertura do serviço. Conforme apontado, para que essa hipótese seja corroborada, os coeficientes do acesso ao serviço e do acesso ao quadrado, além de significativos, devem ser positivos e negativos, respectivamente. 
Os resultados da especificação $\mathrm{V}$ corroboram a hipótese para os três serviços, sinalizando que, no início da consolidação de cada um, a desigualdade de acesso aumenta, mas, uma vez atingido certo nível de cobertura, a desigualdade passa a diminuir. Os resultados da especificação VI continuam a corroborar a hipótese da SHP, porém refutam a hipótese da CK para os casos da coleta de lixo e da coleta de esgoto. No caso do abastecimento de água, a relação $\mathrm{CK}$ ainda existe, mas perdeu significância. As perdas de significância de alguns resultados mostram que a influência da cobertura sobre a desigualdade de acesso prevalece à influência da renda per capita, mas não que esta última não exista, uma vez que as variáveis podem ser colineares. $\mathrm{Na}$ verdade, as variáveis de controle também podem ser colineares, o que influenciaria a significância dos coeficientes. ${ }^{12}$

Em relação às variáveis de controle, poucas alteraçóes se observam ao comparar os resultados das especificaçóes III e IV. Deve-se destacar apenas a taxa de urbanização passando a ter efeitos significativos e negativos para a coleta de lixo e, também nesses casos, a densidade demográfica e a taxa de analfabetismo passando a ter efeitos não significativos.

Deve-se destacar ainda que os modelos estimados não possuem, de manei- ra geral, capacidade relativamente alta de explicar as desigualdades de acesso aos serviços de saneamento ambiental entre os municípios brasileiros, o que se verifica pela análise dos valores da estatística $\mathrm{R}^{2}$. Contudo, esses valores se elevam significativamente nas especificações que consideram a possibilidade de uma SHP (V e VI). Essa é outra evidência favorável à hipótese de uma seletividade hierárquica nos serviços de saneamento ambiental.

Por último, a Tabela 4 apresenta os resultados das estimaçóes considerando a amostra de municípios que possuíam prestadores públicos nos dois anos analisados (1991 e 2000), ou seja, excluindo da amostra total os municípios que, no período, concederam o abastecimento de água e/ ou a coleta de esgoto à iniciativa privada. A análise desta tabela possibilita creditar certa robustez aos resultados encontrados para a amostra total, já que esses não se alteraram ao serem desconsiderados potenciais efeitos da desestatizaçáo.

\section{6_Considerações finais}

O principal objetivo do artigo foi avaliar a questáo da desigualdade de acesso a serviços de saneamento ambiental (coleta de lixo, coleta de esgoto e abastecimento de água), em função da renda dos consumidores (domicílios), apontando se esta é

\footnotetext{
12 Evidências nesse sentido podem ser observadas na Tabela A.1 do Apêndice, que apresenta as correlaçóes entre os controles. Verificam-se correlaçóes elevadas entre algumas variáveis.
} 
Tabela 3_Resultados das estimações (amostra total)

\begin{tabular}{|c|c|c|c|c|c|c|c|c|c|c|}
\hline $\begin{array}{l}\text { Variáveis explicativas } \\
\text { / Especificações }\end{array}$ & \multicolumn{2}{|c|}{ Desigualdade de renda } & \multicolumn{4}{|c|}{$\begin{array}{l}\text { Desigualdade de acesso } \\
\text { Coleta de lixo }\end{array}$} & \multicolumn{4}{|c|}{ Coleta de esgoto } \\
\hline \multirow{2}{*}{$\begin{array}{l}\text { Renda Municipal } \\
\text { per capita }\end{array}$} & $2,946^{(\mathrm{a})}$ & $1,496^{(a)}$ & $-1,517^{(\mathrm{b})}$ & $-1,807^{(a)}$ & & 0,155 & $-2,408^{(a)}$ & $-2,449^{(a)}$ & & $-1,352^{(a)}$ \\
\hline & $(0,259)$ & $(0,246)$ & $(0,653)$ & $(0,662)$ & & $(0,470)$ & $(0,454)$ & $(0,457)$ & & $(0,363)$ \\
\hline \multirow{2}{*}{$\begin{array}{l}\text { Renda Municipal } \\
\text { per capita }^{2}\end{array}$} & $-0,562^{(a)}$ & $-0,295^{(a)}$ & $0,398^{(a)}$ & $0,456^{(a)}$ & & 0,015 & $0,549^{(a)}$ & $0,557^{(\mathrm{a})}$ & & $0,299^{(\mathrm{a})}$ \\
\hline & $(0,053)$ & $(0,050)$ & $(0,137)$ & $(0,139)$ & & $(0,098)$ & $(0,095)$ & $(0,095)$ & & $(0,076)$ \\
\hline \multirow{2}{*}{$\begin{array}{l}\text { Renda Municipal } \\
\text { per capita }^{3}\end{array}$} & $0,036^{(a)}$ & $0,021^{(\mathrm{a})}$ & $-0,033^{(a)}$ & $-0,037^{(a)}$ & & $-0,005$ & $-0,040^{(a)}$ & $-0,041^{(\mathrm{a})}$ & & $-0,022^{(a)}$ \\
\hline & $(0,004)$ & $(0,003)$ & $(0,010)$ & $(0,010)$ & & $(0,007)$ & $(0,007)$ & $(0,007)$ & & $(0,005)$ \\
\hline \multirow[t]{2}{*}{ Acesso } & & & & & $1,424^{(a)}$ & $1,291^{(\mathrm{a})}$ & & & $1,269^{(a)}$ & $1,263^{(\mathrm{a})}$ \\
\hline & & & & & $(0,030)$ & $(0,038)$ & & & $(0,028)$ & $(0,028)$ \\
\hline \multirow[t]{2}{*}{ Acesso $^{2}$} & & & & & $-1,691^{(a)}$ & $-1,500^{(a)}$ & & & $-1,484^{(a)}$ & $-1,479^{(a)}$ \\
\hline & & & & & $(0,027)$ & $(0,038)$ & & & $(0,037)$ & $(0,038)$ \\
\hline Desigualdade de & & & & $0,111^{(\mathrm{a})}$ & $0,095^{(a)}$ & $0,123^{(a)}$ & & $-0,003$ & 0,021 & $0,032^{(\mathrm{b})}$ \\
\hline Renda & & & & $(0,025)$ & $(0,020)$ & $(0,021)$ & & $(0,018)$ & $(0,014)$ & $(0,014)$ \\
\hline \multirow[t]{2}{*}{ Taxa de Urbanização } & & $-0,039^{(a)}$ & 0,016 & 0,022 & $-0,039^{(a)}$ & $-0,025^{(c)}$ & 0,000 & 0,000 & $-0,007$ & $-0,005$ \\
\hline & & $(0,008)$ & $(0,017)$ & $(0,017)$ & $(0,015)$ & $(0,014)$ & $(0,011)$ & $(0,011)$ & $(0,008)$ & $(0,008)$ \\
\hline Densidade & & $0,004^{(\mathrm{a})}$ & $-0,016^{(a)}$ & $-0,017^{(a)}$ & $-0,006$ & $-0,007$ & $0,007^{(a)}$ & $0,007^{(\mathrm{a})}$ & $0,004^{(a)}$ & $0,004^{(a)}$ \\
\hline Demográfica & & $(0,001)$ & $(0,006)$ & $(0,006)$ & $(0,005)$ & $(0,005)$ & $(0,001)$ & $(0,001)$ & $(0,001)$ & $(0,001)$ \\
\hline \multirow[t]{2}{*}{ População } & & $0,034^{(\mathrm{a})}$ & $0,074^{(a)}$ & $0,067^{(\mathrm{a})}$ & $0,127^{(\mathrm{a})}$ & $0,121^{(\mathrm{a})}$ & $-0,014$ & $-0,014$ & 0,006 & 0,011 \\
\hline & & $(0,009)$ & $(0,026)$ & $(0,026)$ & $(0,019)$ & $(0,019)$ & $(0,015)$ & $(0,016)$ & $(0,011)$ & $(0,012)$ \\
\hline \multirow[t]{2}{*}{ Taxa de Analfabetismo } & & $0,040^{(a)}$ & $0,077^{(\mathrm{b})}$ & $0,069^{(\mathrm{b})}$ & 0,030 & $-0,003$ & $0,048^{(b)}$ & $0,049^{(\mathrm{b})}$ & $0,038^{(a)}$ & $0,026^{(c)}$ \\
\hline & & $(0,011)$ & $(0,030)$ & $(0,030)$ & $(0,024)$ & $(0,024)$ & $(0,020)$ & $(0,020)$ & $(0,014)$ & $(0,015)$ \\
\hline Demais Controles & Não & Sim & Sim & Sim & Sim & Sim & Sim & Sim & Sim & Sim \\
\hline \multirow[t]{2}{*}{ Dummy Ano } & 0,002 & 0,012 & $-0,094^{(\mathrm{a})}$ & $-0,098^{(a)}$ & $-0,059^{(a)}$ & $-0,038^{(b)}$ & 0,016 & 0,017 & $-0,029^{(a)}$ & $-0,023^{(\mathrm{b})}$ \\
\hline & $(0,003)$ & $(0,008)$ & $(0,021)$ & $(0,021)$ & $(0,017)$ & $(0,017)$ & $(0,014)$ & $(0,014)$ & $(0,011)$ & $(0,011)$ \\
\hline \multirow[t]{2}{*}{ Constante } & $-4,626^{(a)}$ & $-2,679^{(a)}$ & 1,106 & $1,809^{(\mathrm{c})}$ & $-1,147^{(a)}$ & $-1,349^{(\mathrm{c})}$ & $3,424^{(a)}$ & $3,487^{(a)}$ & $-0,117$ & $1,929^{(\mathrm{a})}$ \\
\hline & $(0,418)$ & $(0,410)$ & $(1,046)$ & $(1,070)$ & $(0,241)$ & $(0,771)$ & $(0,732)$ & $(0,739)$ & $(0,155)$ & $(0,579)$ \\
\hline Observaçóes & 9.967 & 9.954 & 9.667 & 9.653 & 9.653 & 9.653 & 9.950 & 9.936 & 9.936 & 9.936 \\
\hline Grupos & 5.492 & 5.490 & 5.498 & 5.490 & 5.490 & 5.490 & 5.481 & 5.473 & 5.473 & 5.473 \\
\hline Prob $>$ F & 0,000 & 0,000 & 0,000 & 0,000 & 0,000 & 0,000 & 0,000 & 0,000 & 0,000 & 0,000 \\
\hline $\mathrm{R}^{2}$ & 0,006 & 0,080 & 0,123 & 0,141 & 0,365 & 0,388 & 0,011 & 0,011 & 0,484 & 0,478 \\
\hline Teste de Hausman & 0,000 & 0,000 & 0,000 & 0,000 & 0,000 & 0,000 & 0,000 & 0,000 & 0,000 & 0,000 \\
\hline
\end{tabular}

Observaçōes: Erros-padrão entre parênteses. ${ }^{(a)}$ Significativo a $1 \%$. ${ }^{(b)}$ Significativo a $5 \%$. ${ }^{\left({ }^{(c)}\right.}$ Significativo a $10 \%$. 
Tabela 3_Resultados das estimações (amostra total)

\begin{tabular}{|c|c|c|c|c|}
\hline $\begin{array}{l}\text { Variáveis explicativas } \\
\text { / Especificações }\end{array}$ & \multicolumn{4}{|c|}{$\begin{array}{l}\text { Desigualdade de acesso } \\
\text { Abastecimento de água }\end{array}$} \\
\hline \multirow{2}{*}{$\begin{array}{l}\text { Renda Municipal } \\
\text { per capita }\end{array}$} & $1,442^{(\mathrm{b})}$ & $1,192^{(\mathrm{b})}$ & & 0,171 \\
\hline & $(0,581)$ & $(0,592)$ & & $(0,563)$ \\
\hline \multirow{2}{*}{$\begin{array}{l}\text { Renda Municipal } \\
\text { per capita }\end{array}$} & $-0,294^{(\mathrm{b})}$ & $-0,244^{(\mathrm{b})}$ & & $-0,028$ \\
\hline & $(0,118)$ & $(0,120)$ & & $(0,114)$ \\
\hline \multirow{2}{*}{ 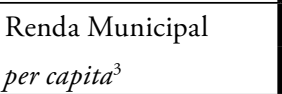 } & $0,019^{(\mathrm{b})}$ & $0,015^{(c)}$ & & 0,003 \\
\hline & $(0,008)$ & $(0,008)$ & & $(0,008)$ \\
\hline \multirow[t]{2}{*}{ Acesso } & & & $1,001^{(\mathrm{a})}$ & $1,015^{(\mathrm{a})}$ \\
\hline & & & $(0,046)$ & $(0,046)$ \\
\hline \multirow[t]{2}{*}{ Acesso $^{2}$} & & & $-1,139^{(a)}$ & $-1,147^{(a)}$ \\
\hline & & & $(0,046)$ & $(0,046)$ \\
\hline \multirow{2}{*}{$\begin{array}{l}\text { Desigualdade de } \\
\text { Renda }\end{array}$} & & $0,089^{(\mathrm{a})}$ & $0,041^{(\mathrm{c})}$ & $0,086^{(a)}$ \\
\hline & & $(0,025)$ & $(0,023)$ & $(0,023)$ \\
\hline \multirow[t]{2}{*}{ Taxa de Urbanização } & 0,015 & 0,021 & $-0,027$ & $-0,010$ \\
\hline & $(0,018)$ & $(0,018)$ & $(0,017)$ & $(0,017)$ \\
\hline Densidade & $-0,015^{(a)}$ & $-0,016^{(a)}$ & $-0,014^{(\mathrm{a})}$ & $-0,015^{(a)}$ \\
\hline Demográfica & $(0,002)$ & $(0,002)$ & $(0,002)$ & $(0,002)$ \\
\hline \multirow[t]{2}{*}{ População } & $0,044^{(\mathrm{c})}$ & 0,039 & $0,052^{(\mathrm{b})}$ & $0,038^{(c)}$ \\
\hline & $(0,024)$ & $(0,023)$ & $(0,022)$ & $(0,021)$ \\
\hline \multirow[t]{2}{*}{ Taxa de Analfabetismo } & $0,056^{(b)}$ & $0,049^{(c)}$ & $0,064^{(\mathrm{b})}$ & 0,036 \\
\hline & $(0,027)$ & $(0,027)$ & $(0,025)$ & $(0,025)$ \\
\hline Demais Controles & Sim & Sim & Sim & Sim \\
\hline \multirow[t]{2}{*}{ Dummy Ano } & $-0,023$ & $-0,026$ & $-0,002$ & 0,015 \\
\hline & $(0,019)$ & $(0,019)$ & $(0,018)$ & $(0,018)$ \\
\hline \multirow[t]{2}{*}{ Constante } & $-2,982^{(a)}$ & $-2,396^{(\mathrm{b})}$ & $-0,813^{(\mathrm{a})}$ & $-0,736$ \\
\hline & $(0,964)$ & $(0,994)$ & $(0,273)$ & $(0,948)$ \\
\hline Observaçôes & 9.968 & 9.954 & 9.954 & 9.954 \\
\hline Grupos & 5.498 & 5.490 & 5.490 & 5.490 \\
\hline Prob $>F$ & 0,000 & 0,000 & 0,000 & 0,000 \\
\hline $\mathrm{R}^{2}$ & 0,075 & 0,088 & 0,230 & 0,211 \\
\hline Teste de Hausman & 0,000 & 0,000 & 0,000 & 0,000 \\
\hline
\end{tabular}

Observaçôes: Erros-padrăo entre parênteses. ${ }^{(a)}$ Significativo a $1 \%$. ${ }^{(b)}$ Significativo a $5 \%$. ${ }^{\left({ }^{(c)}\right.}$ Significativo a $10 \%$. 
Tabela 4_Resultados das estimações para as especificações III, IV, V e VII (amostra de prestadores públicos)

\begin{tabular}{|c|c|c|c|c|c|c|c|c|}
\hline \multirow{2}{*}{$\begin{array}{l}\text { Variáveis explicativas / } \\
\text { Especificações }\end{array}$} & \multicolumn{4}{|c|}{ Coleta de esgoto } & \multicolumn{4}{|c|}{ Abastecimento de água } \\
\hline & III & IV & V & VI & III & IV & V & VI \\
\hline \multirow{2}{*}{$\begin{array}{l}\text { Renda Municipal } \\
\text { per capita }\end{array}$} & $-2,514^{(a)}$ & $-2,562^{(a)}$ & & $-1,376^{(a)}$ & $1,422^{(\mathrm{b})}$ & $1,174^{(\mathrm{b})}$ & & 0,092 \\
\hline & $(0,468)$ & $(0,470)$ & & $(0,374)$ & $(0,585)$ & $(0,597)$ & & $(0,569)$ \\
\hline \multirow{2}{*}{$\begin{array}{l}\text { Renda Municipal } \\
\text { per capita }^{2}\end{array}$} & $0,570^{(a)}$ & $0,579^{(\mathrm{a})}$ & & $0,304^{(\mathrm{a})}$ & $-0,293^{(\mathrm{b})}$ & $-0,244^{(\mathrm{b})}$ & & $-0,015$ \\
\hline & $(0,098)$ & $(0,098)$ & & $(0,079)$ & $(0,119)$ & $(0,121)$ & & $(0,116)$ \\
\hline \multirow{2}{*}{$\begin{array}{l}\text { Renda Municipal } \\
\text { per capita }\end{array}$} & $-0,042^{(\mathrm{a})}$ & $-0,042^{(\mathrm{a})}$ & & $-0,022^{(a)}$ & $0,019^{(\mathrm{b})}$ & $0,015^{(c)}$ & & $-0,001$ \\
\hline & $(0,007)$ & $(0,007)$ & & $(0,005)$ & $(0,008)$ & $(0,008)$ & & $(0,008)$ \\
\hline \multirow[t]{2}{*}{ Acesso } & & & $1,272^{(a)}$ & $1,266^{(a)}$ & & & $0,999^{(a)}$ & $1,014^{(\mathrm{a})}$ \\
\hline & & & $(0,028)$ & $(0,028)$ & & & $(0,047)$ & $(0,047)$ \\
\hline \multirow[t]{2}{*}{ Acesso $^{2}$} & & & $-1,487^{(a)}$ & $-1,482^{(a)}$ & & & $-1,136^{(a)}$ & $-1,143^{(a)}$ \\
\hline & & & $(0,038)$ & $(0,038)$ & & & $(0,047)$ & $(0,047)$ \\
\hline \multirow{2}{*}{$\begin{array}{l}\text { Desigualdade de } \\
\text { Renda }\end{array}$} & & $-0,001$ & 0,023 & $0,033^{(\mathrm{b})}$ & & $0,086^{(a)}$ & $0,038^{(\mathrm{c})}$ & $0,083^{(\mathrm{a})}$ \\
\hline & & $(0,018)$ & $(0,014)$ & $(0,014)$ & & $(0,025)$ & $(0,023)$ & $(0,023)$ \\
\hline Controles & Sim & Sim & Sim & Sim & Sim & Sim & Sim & Sim \\
\hline \multirow[t]{2}{*}{ Dummy Ano } & 0,017 & 0,017 & $-0,029^{(a)}$ & $-0,024^{(b)}$ & $-0,026$ & $-0,029$ & $-0,005$ & 0,011 \\
\hline & $(0,014)$ & $(0,014)$ & $(0,011)$ & $(0,011)$ & $(0,019)$ & $(0,019)$ & $(0,018)$ & $(0,018)$ \\
\hline \multirow[t]{2}{*}{ Constante } & $3,682^{(a)}$ & $3,760^{(a)}$ & $-0,116$ & $1,970^{(a)}$ & $-3,024^{(\mathrm{a})}$ & $-2,440^{(\mathrm{b})}$ & $-0,923^{(a)}$ & $-0,695$ \\
\hline & $(0,751)$ & $(0,758)$ & $(0,157)$ & $(0,596)$ & $(0,960)$ & $(0,991)$ & $(0,268)$ & $(0,948)$ \\
\hline Observaçóes & 9.766 & 9.752 & 9.752 & 9.752 & 9.760 & 9.746 & 9.746 & 9.746 \\
\hline Grupos & 5.374 & 5.366 & 5.366 & 5.366 & 5.376 & 5.368 & 5.368 & 5.368 \\
\hline Prob $>$ F & 0,000 & 0,000 & 0,000 & 0,000 & 0,000 & 0,000 & 0,000 & 0,000 \\
\hline $\mathrm{R}^{2}$ & 0,005 & 0,004 & 0,486 & 0,481 & 0,066 & 0,079 & 0,234 & 0,227 \\
\hline Teste de Hausman & 0,000 . & 0,000 . & 0,000 . & 0,000 . & 0,000 . & 0,000 . & 0,000 . & 0,000 . \\
\hline
\end{tabular}

Observaçōes: Erros-padrão entre parênteses. (a) Significativo a 1\%. (b) Significativo a 5\%. (c) Significativo a 10\%. 
determinada apenas pela capacidade de pagamento desigual desses ou se aspectos relacionados à oferta também devem ser considerados. Para atingir esse objetivo, foram testadas três hipóteses, por meio de estimações para um painel de municípios com dados censitários referentes a 1991 e a 2000:

1_ existiria relação positiva entre a desigualdade de acesso e a desigualdade de renda;

2_ se a desigualdade de renda tiver como consequência a desigualdade de acesso, entáo esta também deveria apresentar relação com o desenvolvimento econômico semelhante à Curva de Kuznets (CK), no formato de um "U-invertido" ou de um "N";

3_ existiria uma Seletividade Hierárquica das Politicas (SHP) no setor.

A primeira hipótese começou a ser testada ainda na terceira seção, com a construção de um indicador municipal de desigualdade de acesso que leva em conta a diferença da cobertura entre os domicílios mais ricos e mais pobres. A análise descritiva da seção mostrou que, na média, esses indicadores eram positivos, em $1991 \mathrm{e}$ em 2000, e que existiam poucos casos de municípios nos quais o acesso nos domicílios mais pobres era maior do que nos mais ricos.

Contudo, as estimações mostraram que a distribuição desigual da capacidade de pagamento dos consumidores (indicador municipal de desigualdade de renda) é uma variável que explica parcialmente a desigualdade de acesso apenas nos casos do abastecimento de água e da coleta de lixo, o que torna necessária a consideração de outros possíveis determinantes, principalmente os aspectos políticos. Evidências nesse sentido também foram observadas ao testar a segunda hipótese, uma vez que, para a proxy de desigualdade de renda municipal adotada, chegouse a uma CK no formato de um " $N$ ", mas uma relação semelhante só foi encontrada para o abastecimento de água. Nos casos da coleta de lixo e da coleta de esgoto, não foram encontradas relações nem no formato de um "U-invertido".

Todavia, as estimações mostraram que a distribuição desigual da capacidade de pagamento dos consumidores (indicador municipal de desigualdade de renda) é uma variável que explica parcialmente a desigualdade de acesso apenas nos casos do abastecimento de água e da coleta de lixo, o que torna necessária a consideração de outros possíveis determinantes, principalmente os aspectos 
políticos. Evidências nesse sentido também foram observadas ao testar a segunda hipótese, já que, para a desigualdade de renda municipal, se chegou a uma CK no formato de um "N", mas uma relação semelhante só foi encontrada para o abastecimento de água. Nos casos da coleta de lixo e da coleta de esgoto, não foram encontradas relaçóes nem no formato de um "U-invertido".

É importante ressaltar que os resultados distintos entre os serviços podem decorrer dos diferentes estágios de consolidação da cobertura desses. Outros fatores como diferenças de custos, de cobrança, de preferências dos indivíduos e, assim, de motivações políticas (eleitorais) também podem explicar os resultados. Tais fatores, comentados ao longo do trabalho, não foram avaliados, o que pode motivar estudos futuros a fazerem essa análise.

Deve-se apontar que as análises mostraram evidências que corroboram a terceira hipótese, ou seja, que sinalizaram a existência de uma seletividade hierárquica das políticas voltadas ao setor. Pode-se dizer que os resultados, nesse sentido, são robustos, visto que foram observados nos três serviços, nas duas especificaçóes e nas duas amostras de municípios. Portanto, no início da consolidação da cobertura, a desigualdade de acesso aumenta, mas passa a reduzir a partir de certo nível. Assim, a relação entre a desigualdade de acesso e a cobertura dos serviços assume o formato de um "U-invertido".

A hipótese da SHP foi retirada da literatura de Sociologia e ainda é pouco explorada em trabalhos econômicos. $\mathrm{O}$ presente estudo fez o primeiro esforço em formalizar uma maneira de testá-la com dados municipais em painel, utilizando os serviços de saneamento ambiental como exemplos e considerando o diferencial de renda entre os domicílios. Essa é outra agenda de estudos que pode se abrir com base nos resultados encontrados.

Por último, é importante ressaltar que as evidências deste estudo indicaram que a desigualdade de acesso em função da renda dos consumidores (domicílios) náo reflete apenas a capacidade desigual desses de pagarem pelos serviços, mas, sim, deficiências na oferta dos serviços. Como esses são providos predominantemente por prestadores públicos, fatores políticos influenciam o problema o que se percebe pela existência de uma seletividade hierárqui$\mathrm{ca}-\mathrm{o}$ aumento do acesso se inicia pelos segmentos da populaçáo economicamente mais favorecidos. Contudo, deve-se levar em conta que são serviços essenciais que, se ofertados inadequadamente, geram externalidades sobre o meio ambiente, a saúde pública e, consequentemente, o desenvolvimento econômico. 
Assim, a provisão deve levar em conta os retornos sociais que podem ser gerados. Como as evidências sugerem que o desenvolvimento econômico pode não solucionar o problema, há a necessidade de políticas que garantam a oferta dos serviços e que viabilizem o acesso da população de menor renda, como, por exemplo, a adoção de alguma forma de tarifação social, como subsídios diretos ou cruzados. Outras possibilidades seriam modelos de provisão dos serviços por meio de concessóes e de parcerias público-privadas, com o setor público atuando na parcela da populaçáo com menor capacidade de pagamento ou com a utilização de mecanismos de complementaçáo de receitas a prestadores privados que alcancem a universalização dos serviços. 


\section{Referências bibliográficas}

AERTS, M.; CLAESKENS, G. Local polynomial estimation in multiparameter likelihood models. Journal of the American Statistical Association, v. 92,

n. 440, Dec., 1997.

AGHION, P.; BOLTON, P.

Distribution and growth in models of imperfect capital markets. European Economic Review, 1992

AHLUWALIA, M. S. Income distribution and development: Some stylized facts. The American Economic Review, 1976.

ALESINA, A.; GLAESER, E. L. Fighting poverty in the U.S. and Europe: A world of difference. Oxford: Oxford University Press, 2004.

ALESINA, A.; RODRIK, D. Distributive politics and economic growth. Quarterly Journal of Economics, 1994.

ANAND, S.; KANBUR, S. M. R. The Kuznets process and the inequality-development relationship. Journal of Development Economics, v. $40,1993$.
ANGRIST, J. D.; PISCHKE, J.

S. Mostly harmless econometrics:

An empiricist's companion.

Princeton University Press,

Princeton, 2009.

BAGOLIN, I. P.; GABE, J.; RIBEIRO, E. P.. Crescimento e desigualdade no Rio Grande do Sul: Uma revisão da Curva de Kuznets para os municípios gaúchos (1970-1991). ENCONTRO DE ECONOMIA GAÚCHA, 2 . 2004, Porto Alegre. Anais.. Porto Alegre, 2004

BALTAGI, B. H. Econometric Analysis of Panel Data. Wiley and Sons Ltda., 2001.

BARROS, L. C.; GOMES, F. A. R. Desigualdade e desenvolvimento: A hipótese de Kuznets é valida para os municípios brasileiros? Revista Análise Econômica, Porto Alegre, n. 50, (26), set., 2008.

BÊRNI, D. A.; MARQUETTI, A.; KLOECKNER, R. A desigualdade econômica do Rio Grande do Sul: Primeiras investigaçóes sobre a Curva de Kuznets. ENCONTRO DE ECONOMIA GAÚCHA, 1., 2004, Porto Alegre. Anais...

Porto Alegre, 2004
BICHIR, R. Determinantes do acesso à infraestrutura urbana no município de São Paulo. Revista Brasileira de Ciências Sociais, 2009. BISHOP, J. A.; FORMBY, J. P.; THISTLE, P. D. Changes in US Earnings Distributions in the 1980s. Applied Economics, 1991.

BNDES. Saneamento: o objetivo é a eficiência. Informes InfraEstrutura, no 23, jun. 1998.

DAHAN, M.; TSIDDON, D. Demographic transition, the distribution of income and economic growth. Journal of Economic Growth, 1998.

DEUTSCH, J., SILBER, J. The Kuznets curve and the impact of various income sources on the link between inequality and development. Working Paper BarIlan University, 2000.

FIELDS, G. S.; JAKUBSON, G. H. New evidence on the Kuznets Curve. Working Paper Cornell University, 1994.

FIGUEIREDO, E. A.; SILVA JÚNIOR, J. C. A.; JACINTO, P. A. A hipótese de Kuznets para os municípios brasileiros: Testes para as formas funcionais e estimaçôes não-paramétricas. Revista Economia, jan.-abr., 2011.
GALIANI, S.; GERTLER, P.; SCHARGRODSKY, E. Water for life: The impact of the privatization of water services on child mortality.

Journal of Political Economy, v. 113, n. 1, 2005.

GALOR, O.; TSIDDON, D. Income distribution and growth: Kuznets hypothesis revisited.

Economica, 1996.

GLAESER, E. L. Inequality. NBER Working Paper Series, 2005.

GRADSTEIN, M.; JUSTMAN, $M$. The democratization of political elites and the decline in inequality in modern economic growth. In: BREZIS, E.; TEMIN, P. (Eds.). Elites, Minorities, and Economic Growth. Amsterdam: Elsevier, 1999.

GREENE, W. H. Econometric Analysis. 3. ed. New Jersey, Prentice Hall, 1997. 
JACINTO, P. A.; TEJADA, C. A. O. Desigualdade de renda e crescimento econômico nos municípios da região nordeste do Brasil: $\mathrm{O}$ que os dados têm a dizer? ENCONTRO NACIONAL DE ECONOMIA, 32., 2004, João Pessoa. Anais... João Pessoa: Associação Nacional do Centros de Pós-Graduação em Economia (ANPEC), 2004.

JHA, S. K. The Kuznets Curve:

A reassessment. World

Development, 1996.

JONES, M. C.; DAVIES, S. J.; PARK, B. U. Versions of Kerneltype regression estimators. Journal of the American Statistical Association, v. 89, n. 427, Sept., 1994.

KATZ, L.; MURPHY, K. Changes in relative wages, 1963-1987: Supply and demand factors. Quarterly Journal of

Economics, 1992.

KUZNETS, S. Economic growth and income inequality. American Economic Review, 1955.

LIST, J. A.; GALLET, C. A. The Kuznets curve: What happens after the inverted-U. Review of Development Economics, 1999.

MARQUES, E. Estado e redes sociais: Permeabilidade e coesão nas políticas urbanas no Rio de Janeiro. Revan/Fapesp, 2000.

MARQUES, E.; BICHIR,

R. Investimentos públicos, infraestrutura urbana e produção da periferia em São Paulo. Espaço \& Debates, 2001.
MENDONÇA, M. J. C.;

GUTIERREZ, M. B. S.; SACHSIDA, A.; LOUREIRO, P. R.

A. Demanda por saneamento no Brasil: Uma aplicação do modelo logit multinomial. Economia Aplicada, v. 8, n. 1, p. 143-163, 2004.

MOTTA, R. S. Questóes regulatórias do setor de saneamento no Brasil. Notas Técnicas do IPEA, 2004.

PEROTTI, 6 Political equilibrium, income distribution and growth: Theory and evidence. Review of Economic Studies, 1993.

PIKETTY, T. The Kuznets Curve: Yesterday and tomoroow. In: BANERJEE, A. V. et al. (Eds.). Understanding Porverty, Oxford University Press, 2006.

REZENDE, S. C.; WAJNMAN, S.; CARVALHO, J. A. M.; HELLER, L. Integrando oferta e demanda de serviços de saneamento: Análise hierárquica do panorama urbano brasileiro no ano 2000. Revista de Engenharia Sanitária Ambiental, 2007.

RUPPERT, D.; WAND, M. P. Multivariate locally weighted least squares regression. The Annals of Statistics, v. 22, n. 3, Sept., 1994.

SAIANI, C. C. S. Déficit de acesso aos serviços de saneamento básico no Brasil. Prêmio IPEA-CAIXA 2006, Brasília, 2006.
SALVATO, M. A.; ALVARENGA, P. S.; FRANÇA, C. S.; ARAÚJO JÚNIOR, A. F. Crescimento e desigualdade: Evidências da Curva de Kuznets para os municípios de Minas Gerais 1991/2000. Ibmec MG Working Paper, n. 33, 2006.

THORNTON, J. The Kuznets inverted-U hypothesis: Panel data evidence from 96 countries. Applied Economics Letters, 2001.

VARIAN, H. R. Redistributive taxation as social insurance. Journal of Public Economics, North-Holland Publishing Company, 1980.

WOOLDRIDGE, J. M.

Introductory Econometrics.

Pioneira Thomson Learning, 20. ed., 2002. 
Apêndice

Tabela A.1_Correlações entre as variáveis de controle (1991 e 2000)

\begin{tabular}{|c|c|c|c|c|c|c|c|c|c|}
\hline Variáveis & $\begin{array}{l}\text { Acesso } \\
\text { (lixo) }\end{array}$ & $\begin{array}{l}\text { Acesso } \\
\text { (esgoto) }\end{array}$ & $\begin{array}{l}\text { Acesso } \\
\text { (água) }\end{array}$ & $\begin{array}{l}\text { Renda munici- } \\
\text { pal per capita }\end{array}$ & $\begin{array}{l}\text { Desigualdade } \\
\text { de renda }\end{array}$ & $\begin{array}{l}\text { Taxa de } \\
\text { urbanização }\end{array}$ & $\begin{array}{l}\text { Densidade } \\
\text { demográfica }\end{array}$ & $\begin{array}{l}\text { Така de } \\
\text { analfabetismo }\end{array}$ & Área \\
\hline Acesso (Esgoto) & $0,613^{(\mathrm{a})}$ & & & & & & & & \\
\hline Acesso (Água) & $0,783^{(\mathrm{a})}$ & $0,576^{(\mathrm{a})}$ & & & & & & & \\
\hline Renda Municipal per capita & $0,731^{(\mathrm{a})}$ & $0,505^{(a)}$ & $0,551^{(\mathrm{a})}$ & & & & & & \\
\hline Desigualdade de Renda & $-0,050^{(a)}$ & $-0,068^{(a)}$ & $-0,012$ & $0,009^{(a)}$ & & & & & \\
\hline Taxa de Urbanização & $0,805^{(\mathrm{a})}$ & $0,509^{(a)}$ & $0,771^{(\mathrm{a})}$ & $0,574^{(\mathrm{a})}$ & $-0,0062$ & & & & \\
\hline Densidade Demográfica & $0,208^{(a)}$ & $0,160^{(a)}$ & $0,191^{(\mathrm{a})}$ & $0,230^{(a)}$ & $-0,034^{(\mathrm{a})}$ & $0,223^{(a)}$ & & & \\
\hline Taxa de Analfabetismo & $-0,622^{(a)}$ & $-0,407^{(a)}$ & $-0,511^{(a)}$ & $-0,782^{(a)}$ & 0,0149 & $-0,475^{(a)}$ & $-0,129^{(a)}$ & & \\
\hline Área & $-0,107^{(\mathrm{a})}$ & $-0,110^{(a)}$ & $-0,118^{(a)}$ & $-0,036^{(a)}$ & $0,161^{(\mathrm{a})}$ & $-0,042^{(a)}$ & $-0,040^{(a)}$ & $0,061^{(a)}$ & \\
\hline População & $0,144^{(\mathrm{a})}$ & $0,119^{(a)}$ & $0,133^{(a)}$ & $0,219^{(a)}$ & $0,052^{\text {(a) }}$ & $0,161^{(\mathrm{a})}$ & $0,438^{(\mathrm{a})}$ & $-0,094^{(a)}$ & 0,012 \\
\hline Setor de Serviços & $-0,304^{(a)}$ & $-0,201^{(a)}$ & $-0,195^{(a)}$ & $-0,376^{(a)}$ & $0,064^{(a)}$ & $-0,262^{(a)}$ & $-0,038^{(a)}$ & $0,378^{(a)}$ & $-0,027^{(a)}$ \\
\hline Taxa de Fecundidade & $-0,610^{(a)}$ & $-0,416^{(a)}$ & $-0,512^{(a)}$ & $-0,608^{(a)}$ & $0,026^{(a)}$ & $-0,418^{(a)}$ & $-0,113^{(a)}$ & $0,719^{(a)}$ & $0,232^{(a)}$ \\
\hline Abaixo de 18 Anos & $-0,650^{(a)}$ & $-0,472^{(a)}$ & $-0,510^{(a)}$ & $-0,701^{(a)}$ & $0,094^{(\mathrm{a})}$ & $-0,385^{(a)}$ & $-0,099^{(a)}$ & $0,751^{(\mathrm{a})}$ & $0,219^{(\mathrm{a})}$ \\
\hline Acima de 65 Anos & $0,151^{(a)}$ & $0,227^{(\mathrm{a})}$ & $0,144^{(a)}$ & $0,096^{(a)}$ & $-0,120^{(\mathrm{a})}$ & $-0,028^{(a)}$ & $-0,070^{(a)}$ & $-0,084^{(a)}$ & $-0,271^{(\mathrm{a})}$ \\
\hline Não Branco & $-0,467^{(\mathrm{a})}$ & $-0,316^{(\mathrm{a})}$ & $-0,299^{(a)}$ & $-0,649^{(a)}$ & $0,170^{(\mathrm{a})}$ & $-0,221^{(\mathrm{a})}$ & $-0,030^{(a)}$ & $0,707^{(a)}$ & $0,179^{(a)}$ \\
\hline Energia e Televisão & $0,791^{(a)}$ & $0,519^{(a)}$ & $0,662^{(a)}$ & $0,737^{(\mathrm{a})}$ & $-0,061^{(a)}$ & $0,600^{(a)}$ & $0,140^{(a)}$ & $-0,798^{(a)}$ & $-0,165^{(a)}$ \\
\hline Carro & $0,635^{(a)}$ & $0,436^{(a)}$ & $0,458^{(a)}$ & $0,857^{(\mathrm{a})}$ & $-0,145^{(a)}$ & $0,373^{(\mathrm{a})}$ & $0,101^{(\mathrm{a})}$ & $-0,806^{(a)}$ & $-0,148^{(a)}$ \\
\hline Telefone & $0,714^{(\mathrm{a})}$ & $0,521^{(\mathrm{a})}$ & $0,581^{(\mathrm{a})}$ & $0,850^{(\mathrm{a})}$ & $-0,018^{(\mathrm{c})}$ & $0,578^{(\mathrm{a})}$ & $0,227^{(\mathrm{a})}$ & $-0,663^{(a)}$ & $-0,053^{(\mathrm{a})}$ \\
\hline Geladeira & $0,762^{(a)}$. & $0,469^{(a)}$ & $0,616^{(a)}$ & $0,816^{(a)}$ & $-0,097^{(\mathrm{a})}$ & $0,569^{(a)}$ & $0,143^{(a)}$. & $-0,861^{(a)}$ & $-0,131^{(a)}$ \\
\hline
\end{tabular}

\begin{tabular}{|c|c|c|c|c|c|c|c|c|c|}
\hline Variáveis & Populaçãa & $\begin{array}{l}\text { Setor de } \\
\text { Serviços }\end{array}$ & $\begin{array}{l}\text { Taxia de } \\
\text { Fecundidade }\end{array}$ & $\begin{array}{l}\text { Abaixo de } \\
18 \text { Anos }\end{array}$ & $\begin{array}{l}\text { Acima de } \\
65 \text { Anos }\end{array}$ & Não Branco & $\begin{array}{l}\text { Energia e } \\
\text { Televisão }\end{array}$ & Carro & Telefone \\
\hline Setor de Serviços & $-0,020^{(c)}$ & & & & & & & & \\
\hline Taxa de Fecundidade & $-0,079^{(a)}$ & $0,190^{(a)}$ & & & & & & & \\
\hline Abaixo de 18 Anos & $-0,057^{(a)}$ & $0,202^{(a)}$ & $0,848^{(a)}$ & & & & & & \\
\hline Acima de 65 Anos & $-0,048^{(a)}$ & $0,176^{(\mathrm{a})}$ & $-0,344^{(a)}$ & $-0,550^{(a)}$ & & & & & \\
\hline Não Branco & $-0,010$ & $0,272^{(a)}$ & $0,611^{(\mathrm{a})}$ & $0,704^{(a)}$ & $-0,273^{(a)}$ & & & & \\
\hline Energia e Televisão & $0,090^{(a)}$ & $-0,274^{(a)}$ & $-0,785^{(a)}$ & $-0,846^{(a)}$ & $0,304^{(\mathrm{a})}$ & $-0,655^{(a)}$ & & & \\
\hline Carro & $0,075^{(\mathrm{a})}$ & $-0,341^{(\mathrm{a})}$ & $-0,682^{(a)}$ & $-0,825^{(a)}$ & $0,290^{(a)}$ & $-0,808^{(a)}$ & $0,790^{(a)}$ & & \\
\hline Telefone & $0,200^{(a)}$ & $-0,288^{(a)}$ & $-0,546^{(a)}$ & $-0,661^{(\mathrm{a})}$ & $0,182^{(a)}$ & $-0,504^{(\mathrm{a})}$ & $0,684^{(a)}$ & $0,783^{(a)}$ & \\
\hline Geladeira & $0,094^{(a)}$ & $-0,349^{(a)}$ & $-0,759^{(a)}$ & $-0,832^{(a)}$ & $0,214^{(\mathrm{a})}$ & $-0,720^{(a)}$ & $0,945^{(\mathrm{a})}$ & $0,871^{(a)}$ & $0,734^{(a}$ \\
\hline
\end{tabular}

Obs.: (a) Significativo a 1\%. (b) Significativo a 5\%. (c) Significativo a 10\%. 
